\title{
Research gaps in scale up of family planning and reproductive health programming
}

The Evidence Project

E2A

HPP

MEASURE Evaluation

Follow this and additional works at: https://knowledgecommons.popcouncil.org/departments_sbsr-rh

Part of the Demography, Population, and Ecology Commons, Family, Life Course, and Society Commons, Health Policy Commons, and the International Public Health Commons How does access to this work benefit you? Let us know!

\section{Recommended Citation}

Evidence Project, E2A, HPP, and MEASURE Evaluation. 2014. "Research gaps in scale up of family planning and reproductive health programming," Meeting report. Washington, DC: Population Council, Evidence Project. 


\section{Research Gaps in Scale Up of}

Family Planning and Reproductive Health Programming

\section{June 23, 2014}

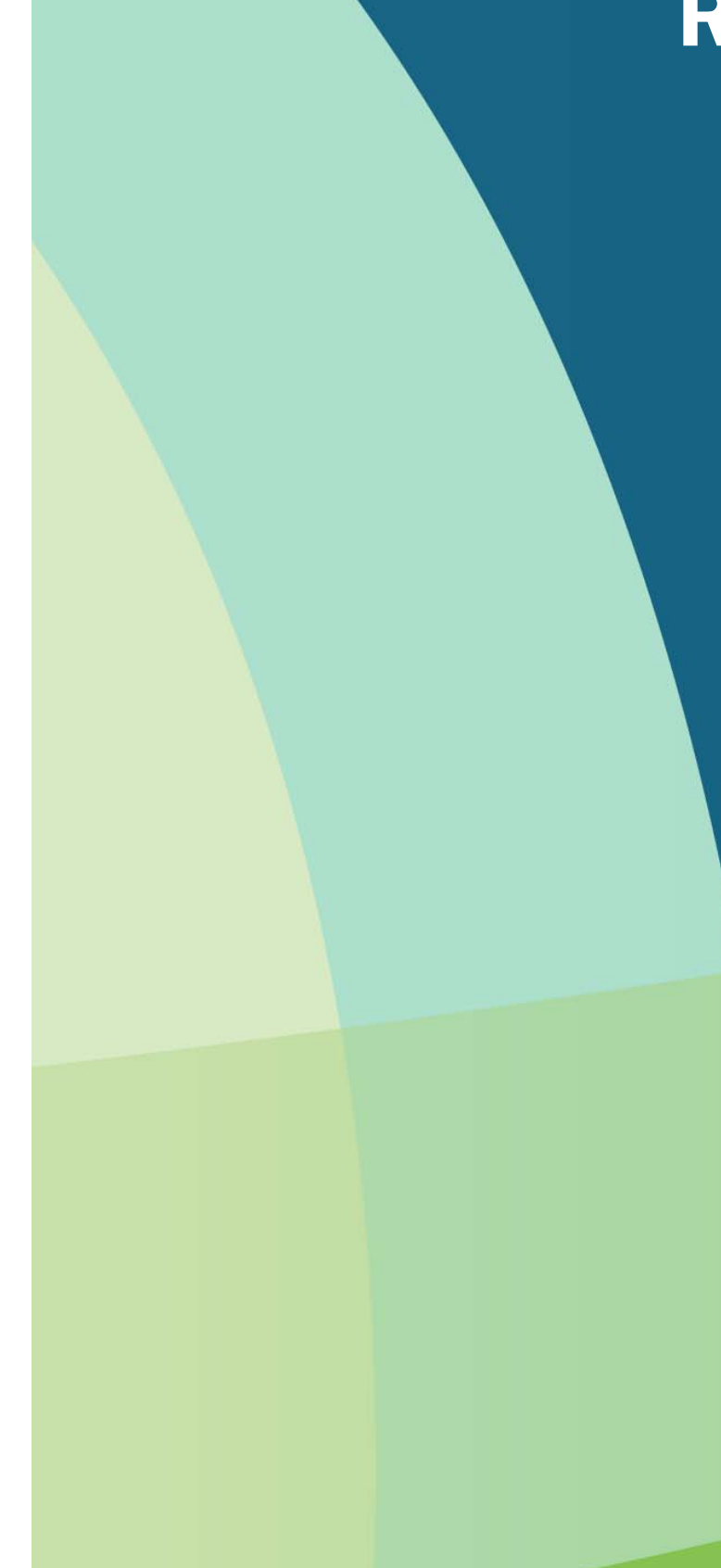




\section{Evidence Project}

Population Council

4301 Connecticut Avenue, NW, Suite 280

Washington, DC 20008 USA

Tel : +12022379400

Email : evidenceproject@popcouncil.org

evidenceproject.popcouncil.org

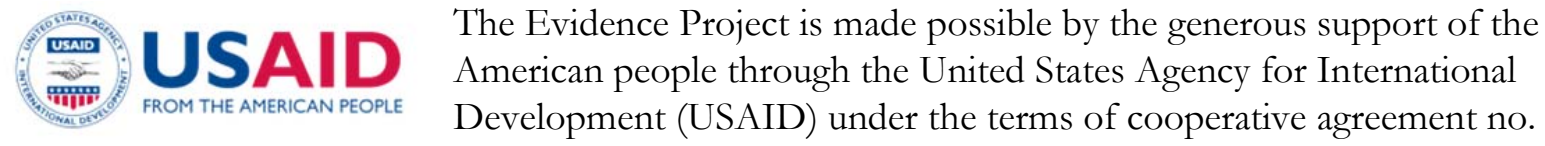

AID-OAA-A-13-00087. The contents of this document are the sole responsibility of the Evidence Project and Population Council and do not necessarily reflect the views of USAID or the United States Government.

\footnotetext{
Evidence The Evidence Project uses implementation science-the strategic generation, translation, and use of evidence - to strengthen and scale up family planning and reproductive health programs to reduce unintended pregnancies worldwide. The Evidence Project is led by the Population Council in partnership with INDEPTH Network, International Planned Parenthood Federation, Management Sciences for Health, PATH, Population Reference Bureau, and a University Resource Network.
}

Published in September 2014

Suggested citation: Evidence Project, E2A, HPP and MEASURE Evaluation. 2014. "Research Gaps in the Scale up of Family Planning and Reproductive Health Programming," Meeting Report. Washington, DC: Population Council, Evidence Project

(C) 2014 The Population Council, Inc. 


\section{Table of Contents}

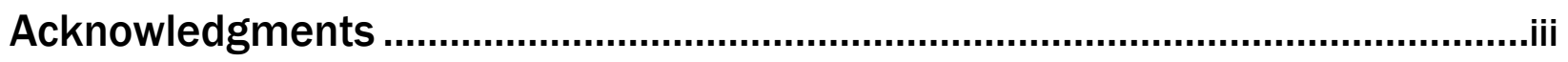

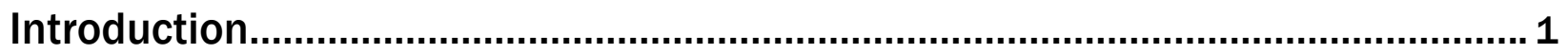

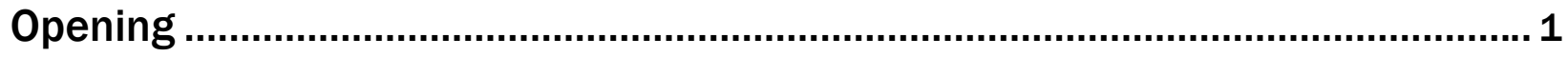

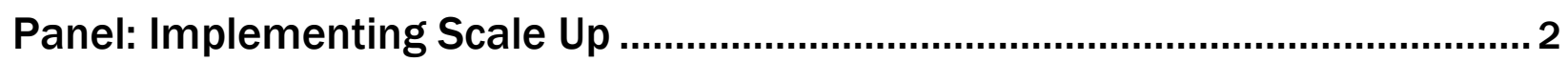

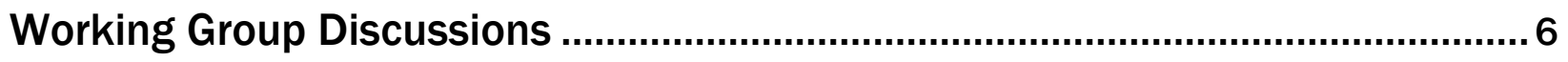

Summary of Key Research Questions and Areas of Support for Scale Up......... 9

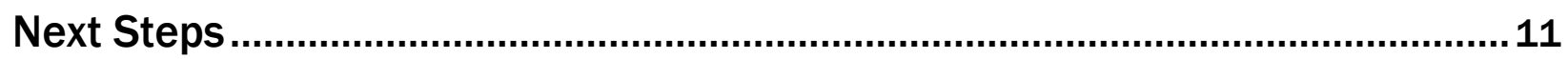

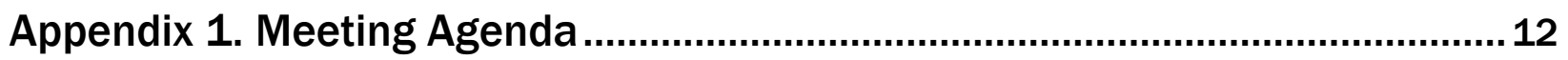

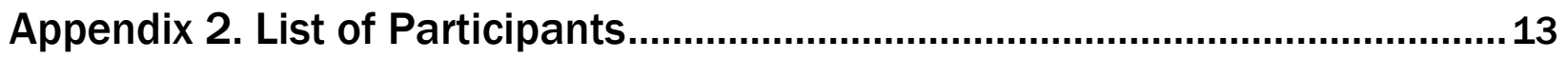

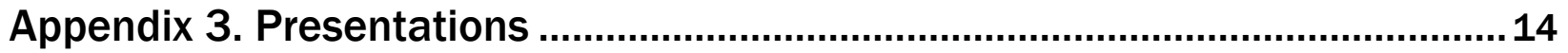

Appendix 4. Notes from the Group Discussions ................................................. 30 


\section{Acknowledgments}

This workshop was funded by the United States Agency for International Development (USAID) through the Evidence Project, in collaboration with the Evidence to Action (E2A) Project, the Health Policy Project (HPP), and MEASURE Evaluation. The organizing committee included: Karen Hardee, Jill Keesbury, Luigi Jaramillo, and Maria Linden from the Evidence Project; Gwen Morgan from E2A; Beth Rottach and Nancy Yinger from HPP; Mahua Mandal and Bridgit Adamou from MEASURE Evaluation; and Shawn Malarcher from USAID. Additionally, Salwa Bitar and Fariyal Fikree from E2A and Rachel Kiesel from HPP served as meeting facilitators. We would like to thank Mihira Karra and Erika Martin of USAID for their support for this meeting. We also thank the speakers: Rebecka Lundgren, Institute for Reproductive Health; Callie Simon, Pathfinder International; Ayman Abelmohsen, Abt Associates; and Dawn Chin-Quee, FHI360. 


\section{Introduction}

This meeting was held at the request of USAID's Office of Population and Reproductive Health $(\mathrm{OPRH})$ to help guide their research strategy. The Evidence Project, in collaboration with the Evidence to Action (E2A) Project, the Health Policy Project (HPP), and MEASURE Evaluation convened this meeting to discuss research gaps related to scale up. See Appendix 1 for the agenda of the meeting and Appendix 2 for a list of participants. The meeting had four objectives:

- Discuss scale up experiences and the role of research and monitoring for strengthening program performance at scale.

- Identify research gaps related to scale up.

- Prioritize the scale up research gaps for OPRH.

- Identify next steps for addressing these priority research gaps.

\section{Opening}

The meeting was opened by Mihira Karra, Chief of the Research, Technology, and Utilization Division of USAID and chaired by Gwen Morgan from the E2A Project. Shawn Malarcher, also from the Research and Utilization Division, set the stage for the meeting (see Appendix 3 for her presentation). She explained that USAID/PRH is seeking clarity on its current investments in research by developing a research agenda, prioritizing its list of research questions, and seeking to improve the quality of research funded. ORPH's research typology includes (i) research methods and measures; (ii) formative research; (iii) contraceptive technologies research; (iv) intervention research; and (iv) research on scale up. The focus of this meeting is to discuss research related to scale up, which USAID defines as introduction or adaptation research that facilitates the adoption/uptake in a local context of a tool, approach, or intervention. USAID is interested in:

- What role research plays in supporting scale up?

- What is the role of core funds in supporting such research?

- Are results from scale-up research generalizable or are they context specific? 


\section{Panel: Implementing Scale Up How Research Did or Could Help the Scale Up Process and Outcomes}

The second session included four presentations on experiences scaling up a family planning practice or an intervention - with particular attention to how research was or could have been useful in the scale up process. See Appendix 3 for the presentations.

\section{YOUTH-FRIENDLY SERVICES (YFS)}

Callie Simon from Pathfinder presented lessons learned from the scale-up of youth-friendly sexual and reproductive health (SRH) services in Ethiopia, Ghana, Mozambique, Vietnam and Tanzania. Details about the programs in the five countries are available in the paper Scale-up of Adolescent Contraceptive Services: Lessons From a 5-Country Comparative Analysis, recently published in JAIDS. Pathfinder used the ExpandNet framework to compare the country experiences with scale up.

In all five of these countries, Pathfinder supported the Ministry of Health and other Ministries to scale up YFS, in collaboration with other partners. The innovation was done slightly different in each country, but in all five countries, a package of adolescent SRH services was offered through the public sector, and in some cases, in private or NGO facilities, and work places. Emphasis was put on privacy, confidentiality, and respectful treatment, all important in services for youth. Services were complemented with activities to strengthen the enabling environment, including addressing gender norms and stigma around adolescents' sexuality that prevent adolescents from seeking services. Youth participation, including involving youth in the monitoring of the quality of the services, was also part of the programs. In all five countries, the programs approached scale up horizontally and vertically. In Ethiopia, Mozambique, and Vietnam scale up took 8-12 years.

Research was not a significant part of the scale up, although there was some research in Ethiopia, Mozambique, and Vietnam. The lack of research was partly because the programs were designed from the beginning to go to scale. When the program staff had come up with research ideas and questions, they were told by the Ministry and donors that the program was for scaling up and that all resources were to be used for this purpose. Research was considered a luxury they could not afford. There were however a few instances of research:

- In Vietnam, an evaluation of the pilot phase informed the selection of type of facility in which to scale YFS.

- In Mozambique, high turnover of female staff was noted during a quarterly review meeting, giving a chance to examine why (because they were not being recruited in the same number as male peer educators or retained in the same way). 
- Ethiopia conducted a study regarding the expansion of long-acting contraceptives.

- Through research Pathfinder has found that what is most important to youth is confidentiality and respectful treatment. This is the foundation of YFS.

Questions that would have benefitted from research include:

- What are the essential features of YFS to further streamline the innovation?

- How feasible is it to reach a greater number of vulnerable youth through scale up?

- What are strategies to improve provider behavior and attitudes?

- More research on the implementation process. What is the most efficient and effective ways of scaling up YFS? What are the costs of scale up?

- What hinders sustainability of the scale up of YFS?

\section{STANDARD DAYS METHOD (SDM)}

Rebecca Lundgren from the Institute for Reproductive Health (IRH) spoke about scale up of the SDM in Rwanda, part of a five-country study on the scale up of SDM. Prior to the scale up process, IRH conducted 12 years of research on the method; during the scale up, along with regular monitoring and evaluation (M\&E), IRH conducted multi-site studies to compare what worked and what did not work in the different countries. The IRH project was a research project and data that were collected during scale up identified elements that were important in the process, such as materials and systems, and IRH was able to evaluate alternative ways in addressing those elements and implement ways that worked better. If it had been funded as an implementation project, they would not have had the resources to do this research. Rebecca noted that this has implications as we discuss what should be funded as far as research, monitoring, learning, and evaluation. Rebecca described how program and process monitoring and research influenced scale up:

- Ongoing M\&E data showed that provider training protocols and client materials that worked in the pilot phase did not work at scale, thus the materials were simplified to support integration into the national program.

- Triangulation of monitoring data with national survey results revealed supply chain problems that affected SDM (and the accompanying CycleBeads ${ }^{\circledR}$ ) availability and use. New procedures for ordering supplies and monitoring stock-outs were instituted at the facility level.

- Supervision reports and special studies revealed that providers were imposing unnecessary medical barriers to SDM use. Refresher training and revised supervision protocols improved provider practices. 
- Normal environmental scans, stakeholder interviews, and key events timelines identified shifting political and health policy environments that influenced scale up outcomes. Ongoing advocacy efforts are addressing these issues.

Ongoing knowledge gaps include:

- Policy barriers to scale-up. Who sets the agenda?

- What has prevented some international donors/organizations from integrating SDM?

- How does the global donor/technical assistance (TA) community influence scale up?

- What are the key environmental influences on scale up and sustainability levels of SDM?

- Equity and scale up. How can we reduce disparities in access to SDM?

- Total market: What is the right mix of subsidized vs. full pay services?

\section{SCALING UP FAMILY PLANNING (SUFP) PROJECT}

Ayman Abelmohsen, from Abt Associates, spoke about the DFID-funded SUFP Project in Zambia. DFID's funding model focuses on value for money, and expected outcomes - defined in the case of this project as scale - which are built into projects from the outset. These expected outcomes that reflect scale included: improving availably of modern FP methods, improving accessibility, fostering community participation, and building public sector capacity to provide services. As a service delivery project, funding was devoted only to monitoring progress toward the outcomes with no support for additional research activities. To achieve its objectives, the project developed what it terms the "camping approach." The camping approach is a set of integrated supply and demand generation interventions that are iteratively designed and implemented in collaboration with the district's health management office. The project rapidly scaled these interventions from seven pilot sites to twenty-six in two years, following a phased approach. To measure progress, the project conducted a baseline study, which allowed it to review the indicators that were set by DFID before the project started, and then set their own targets based on the baseline values. It has recently reached full-scale as set out by the program, and the program is now beginning to reflect on the process of scaling up in order to inform future expansion of the model. Related to research gaps:

- When SUFP worked with the Ministry of Health in designing the camping approach that integrates demand and supply, it proved to be successful under the auspices of the project. But to what extent is this approach scalable beyond the project? Had the funds and time been available from the donor, SUFP could have been able to measure the feasibility of scaling up the model before introducing it. Such research could have examined the extent to which this model contributes to utilization of family planning, and scalability beyond the project. Important questions include the extent to which the government could fund, monitor, and allocate appropriate resources for the model after the donor funding ends. 
- More focus on assessing and responding to the needs of youth. SUFP is trying to introduce YFS, but has yet to find a well-defined package of what is YFS.

- What will it take for the government to take over the project - to integrate it into the existing family planning program and into the health system?

- How effective are the different iterations of the camping model? Which is the most effective?

- What is the cost of the various camping interventions?

\section{COMMUNITY-BASED ACCESS TO INJECTABLES (CBA2I)}

Dawn Chin-Quee from FHI360 presented on preparing the way for scale up research on CBA2I in Uganda. FHI360 collaborated with Save the Children to test the safety and feasibility of CBA2I in the private and public sectors. The approach included: identifying and engaging potential partners; assessing capacity and formalizing partnerships; harmonizing CBA2I with existing health care systems; promoting CBA2I and sensitizing communities; training of community health workers; managing logistics and waste; and monitoring and supervising CHWs. Dawn presented a number of lessons learned through their work under each component of the approach as well as broader lessons, as follows:

- Design interventions with facilitators of/barriers to scale up in mind.

- Engage end-users (those who will scale) throughout.

- Document the process, capture the "how" to inform scale up.

- Integrate costing analysis into pilot research.

- Package key learnings so they can be used to facilitate scale up.

Remaining gaps in research for scale up of CBA2I include:

- Assessing cost-effectiveness of adding injectables to the method mix offered by community health workers (CHWs). FHI360 found that the need for CBA2I in programs must be weighed against the operational costs of providing it.

- Determining how to optimize public and private sector collaboration.

- Determining the best way to provide training and continuous support for procurement/logistics.

- Establishing mechanisms for good quality supportive supervision.

- Increasing CHW capacity to offer/promote a full range of contraceptive options. 


\section{Working Group Discussions}

Following the panel presentations, Bridgit Adamou from MEASURE Evaluation and facilitators from the three hosting projects led group discussions. Participants divided into three working groups to discuss the role of research and monitoring in effective scale-up, and to identify priority research questions related to scale-up. Notes from the discussions are found in Appendix 4.

Some key issues and recommendations that emerged from the discussion include:

\section{ENHANCED KNOWLEDGE MANAGEMENT ABOUT SCALE UP}

Interestingly, a number of participants noted that we already know a lot about the challenges and barriers to scale-up and also about what it takes and the important components to scale-up. They suggested that the issue is that we do not use the information. Yet, these two topics - the challenges and barriers were on the top of the list of topics (listed below) for which we need more information. Perhaps the issue is better knowledge management so that the information known is more accessible to the community interested in scale up.

> Recommendation: Improve knowledge management on scale-up to include not only bibliographies of scale up experiences but also relevant syntheses (e.g. about facilitating factors, the key systems elements, resource needs, the time element and shortening the time needed for scale up, sustainability, etc.)

\section{COUNTRY-LEVEL VS. GLOBAL SUPPORT FOR SCALE UP}

The discussion distinguished between scale up that is supported at the country level that would be funded through national funds and field support from donors (e.g. USAID), and support that would be appropriate from donors at the global level. The distinction is activities that support country-specific scale-up and those that have global implications and thus would benefit from global or core (USAID) funding. Participants noted that projects to scale up interventions are generally considered service delivery projects, with some funding for $\mathrm{M} \& \mathrm{E}$ but generally no funding for research.

Participants also noted that it is important to differentiate between studying proof of concept (does the intervention work) vs. proof of implementation (can the intervention be implemented/scaled up) and the need for an adaption phase which can include testing different elements of the model.

> Recommendation: At the country level, participants recommended the following support from donors to strengthen effective scale-up:

o Funding for a learning agenda, including monitoring and problem solving during scale up. Funds should be specifically designated for M\&E and implementation research to support scale-up, including for TA. 
o Include funding to support and monitor measures of institutionalization as well as coverage to demonstrate successful scale-up.

o Support capacity building for scale up (see section below on capacity building).

> Recommendation: At the global level, participants recommended that resources should support:

o Innovative interventions and approaches to scale up, including:

- Moving from proof of concept to proof of implementation (with an adaption phase) - with scale up funded with country-level funds.

- How to move from pilot to adaption to scale up (e.g. Should fidelity be more clearly addressed at the proof of concept stage before moving to adaptation and scale up?).

- How scale up could be accomplished more efficiently, including faster.

o TA for scale up should be included during the proof of concept, proof of implementation, and adaptation stages. TA for M\&E and implementation research should be supported during scale up (at least initially, with more support for this TA coming from country-level resources.

o Retrospective analysis to document what it takes (time and money) to scale-up various practices.

o Knowledge management to build and disseminate the experience base with scale up - to facilitate lessons learned on key issues in scale up (see next section).

\section{LINKING RESEARCH AND M\&E ON SCALE UP}

Participants noted the need to link research to M\&E. There was a clear call to layer on prospective monitoring and documentation processes that allow us to learn from scale up, but also to conduct retrospective studies to understand the components of successful scale-up.

> Recommendation: Ensure that all scale-up efforts have sufficient resources to ensure that, at a minimum, they are able to conduct robust $M \& E$ and that scale up efforts include a learning agenda that provides scope for implementation research. 


\section{CAPACITY BUILDING}

The topic of capacity building emerged in the presentations and discussion, in relation to capacity building for scale up and also capacity building for research in scale up. Participants noted the need for TA related to scale up.

> Recommendation: Implement a TA agenda to support countries to develop capacities to promote scale up in areas such as M\&E, context-specific operations research, and implementing systematic models of scale up. 


\section{Summary of Key Research Questions and Areas of Support for Scale Up}

Based on the presentations and the group discussions, Nancy Yinger from HPP led a discussion to reach some consensus on priority research questions. The discussion yielded a mix of research questions and areas of support for scale up, including:

\section{CAPACITY BUILDING}

- What are the best ways to enable or develop the capacity of stakeholders in-country to systemically implement and monitor scale-up efforts? What skills are needed? What resources are needed?

\section{FACILITATING FACTORS}

- What are facilitating factors to scale-up and the factors that have hindered scale up and how have those factors been addressed? While the facilitating factors may be known, how those and the barriers - have been addressed, is important to know, both through retrospective case studies and through better knowledge management about scale up.

- What characteristics of implementation foster its success for scale up? What do we know about the components of the scaling up process from implementation experience? What components were the easiest to implement and which were the most difficult. Which components "stuck" and which ones didn't? This is another area that would benefit from retrospective case studies and better knowledge management of lessons learned from scale up.

- What can we leverage and learn from private/commercial sector experiences in scaling up services (e.g. social franchising models)?

- What are the costs of scale up? Are the full costs being adequately captured, including the time dimension of resource needs?

- What is the best way to communicate to national governments, including at the central and decentralized levels, in order to get their buy-in and resources for the scale up?

\section{KEY SYSTEM ELEMENTS}

- What health system elements and contextual factors are essential to scaling up? How have scale up initiatives addressed these systems issues and contextual factors? This is another area that 
would benefit from retrospective case studies and better knowledge management of lessons learned from scale up.

- Is there any diffusion of the intervention to adjacent areas? Is there a tipping point for scale up at which the innovation/intervention will expand spontaneously?

- Is it better for a pilot to be done in a "real world" situation or to be the "bells and whistles" approach? Can pilots include arms that test components of the intervention to determine what components are needed to ensure impact?

- How should pilots be undertaken to lay the ground work for scale? Does the intervention hold (and work as well) when brought to scale?

\section{SHORTENING OF TIME FRAME}

- How can we achieve scale at a faster pace?

\section{BALANCING SUSTAINABILITY WITH EQUITY}

- How can we maintain fidelity and equity of access while simultaneously reaching scale?

- How can we avoid losing equity when reaching scale? 


\section{Next Steps}

This meeting generated a rich discussion about the need to better document the scale up process, particularly the vertical (institutionalization) aspect of scale up. Key questions revolved around determining capacity building for scale, identifying and disseminating the facilitating factors, working with key health system elements as defined by WHO (service delivery, health workforce, information, medical products, vaccines and technologies, financing, and leadership and governance), shortening the scale up time frame, and balancing sustainability with equity. The results of this meeting will be used to inform the OPRH Research Strategy and the work of implementing partners.

Topics for additional meetings, discussions, and work emerged around a number of topics, including better knowledge management around experience with scale up, retrospective case studies on scale up experience, implementation research on improving the efficiency of scale up, the role of country vs. global support of scale up, linking implementation research and M\&E of scale up, and the best metrics for measuring scale up, among others. 


\section{Appendix 1. Meeting Agenda}

\begin{tabular}{|c|c|c|}
\hline Time & Session & Description \\
\hline 8:30-9:00 & Registration and breakfast & \\
\hline 9:00-9:30 & Welcome and introductions & $\begin{array}{l}\text { Mihira Karra, USAID } \\
\text { Gwen Morgan, E2A, Meeting Facilitator }\end{array}$ \\
\hline 9:30-10:00 & Setting the stage for the meeting & Shawn Malarcher, USAID \\
\hline \multirow[t]{8}{*}{ 10:00-12:00 } & \multirow{8}{*}{$\begin{array}{l}\text { Panel - Implementing Scale Up: } \\
\text { How Research Did or Could Help } \\
\text { the Process and Outcomes }\end{array}$} & Karen Hardee, Evidence Project, Moderator \\
\hline & & $\begin{array}{l}\text { Scale up of Contraceptive Services for } \\
\text { Adolescents } \\
\text { Gwen Hainsworth, Pathfinder }\end{array}$ \\
\hline & & $\begin{array}{l}\text { Scale up of Fertility Awareness Methods } \\
\text { Rebecka Lundgren, IRH }\end{array}$ \\
\hline & & Questions/discussion \\
\hline & & 10:45-11:00 - Break \\
\hline & & $\begin{array}{l}\text { Scaling Up An Approach to Family Planning in } \\
\text { Zambia } \\
\text { TBD for Christopher Marimba, Abt Associates } \\
\text { Zambia }\end{array}$ \\
\hline & & $\begin{array}{l}\text { Scale up of CBD of Injectables } \\
\text { Dawn Chin-Quee, FHI360 }\end{array}$ \\
\hline & & Questions/discussion \\
\hline 12:00-1:00 & Lunch & \\
\hline 1:00-3:00 & $\begin{array}{l}\text { Breakout groups on research gaps } \\
\text { in scaling up }\end{array}$ & $\begin{array}{l}\text { Bridgit Adamou, MEASURE Evaluation, } \\
\text { Moderator }\end{array}$ \\
\hline $3: 00-3: 30$ & Break & \\
\hline $3: 30-4: 00$ & Group report back & \multirow[t]{2}{*}{ Nancy Yinger, HPP, Moderator } \\
\hline 4:00-4:30 & $\begin{array}{l}\text { Crafting Recommendations from } \\
\text { the Meeting }\end{array}$ & \\
\hline $4: 30-4: 45$ & Next Steps & Shawn Malarcher, USAID \\
\hline
\end{tabular}




\section{Appendix 2. List of Participants}

\begin{tabular}{|c|c|c|}
\hline Name & Organization & Email Address \\
\hline Abdelmohsen, Ayman & Abt Associates & Ayman_Mohsen@abtassoc.com \\
\hline Adamou, Bridgit & UNC/MEASURE Evaluation & adamou@,email.unc.edu \\
\hline Baker Ndugga, Maggwa & Bill and Melinda Gates Foundation & Maggwa.BakerNdugga@gatesfoundation.org \\
\hline Bitar, Salwa & $\mathrm{E} 2 \mathrm{~A} / \mathrm{MSH}$ & sbitar@e2aproject.org \\
\hline Chattopadhyay, Ishita & Population Council & ishitac@popcouncil.org \\
\hline Chin-Quee, Dawn & FHI360 & dchin-quee@,fhi360.org \\
\hline Cho, Kate & Abt Associates & KateCho@abtassoc.com \\
\hline Cole, Claire & Pathfinder & ccole@pathfinder.org \\
\hline Fehlenberg, Kate & Management Systems International & kfehlenberg@msi-inc.com \\
\hline Fikree, Fariyal & $\mathrm{E} 2 \mathrm{~A}$ & ffikree@,e2aproject.org \\
\hline Gribble, Jay & HPP/Futures Group & jgribble@futuresgroup.com \\
\hline Hardee, Karen & Evidence Project/Population Council & khardee@popcouncil.org \\
\hline Jain, Aparna & Evidence Project/Population Council & apjain@popcouncil.org \\
\hline Jaramillo, Luigi & Evidence Project/MSH & ljaramillo-MSH@popcouncil.org \\
\hline Karra, Mihira & USAID & mkarra@usaid.gov \\
\hline Keeley, Robin & Abt Associates & Robin_Keeley@abtassoc.com \\
\hline Keesbury, Jill & Evidence Project/PATH & jkeesbury-PATH@popcouncil.org \\
\hline Kiesel, Rachel & HPP/Futures Group & rkiesel@,futuresgroup.com \\
\hline Linden, Maria & Evidence Project/Population Council & mlinden@popcouncil.org \\
\hline Lundgren, Rebecka & IRH & rebecka.lundgren.irh@gmail.com \\
\hline MacDonald, Patricia & USAID & pmacdonald@usaid.gov \\
\hline Malarcher, Shawn & USAID & smalarcher@usaid.gov \\
\hline Martin, Erika & USAID & ermartin@usaid.gov \\
\hline Morgan, Gwen & $\mathrm{E} 2 \mathrm{~A} / \mathrm{MSH}$ & gmorgan@e2aproject.org \\
\hline Rottach, Elisabeth & HPP/Futures Group & erottach@,futuresgroup.com \\
\hline Sarpong, Deborah & Evidence Project/Population Council & dsarpong@popcouncil.org \\
\hline Shannon, Caitlin & EngenderHealth & CShannon@engenderhealth.org \\
\hline Simon, Callie & Pathfinder & csimon@pathfinder.org \\
\hline Stephenson, Patricia & USAID & pstephenson@usaid.gov \\
\hline Sussman, Linda & USAID & lsussman@usaid.gov \\
\hline Trasi, Reshma & $\mathrm{MSH}$ & rtrasi@msh.org \\
\hline Velez May, Ados & IPB/WHO & avelezmay@pathfinder.org \\
\hline Wright, Kelsey & Evidence Project/Population Council & kwright@popcouncil.org \\
\hline Yinger, Nancy & HPP/Futures Group & nyinger@futuresgroup.com \\
\hline
\end{tabular}




\section{Appendix 3. Presentations}

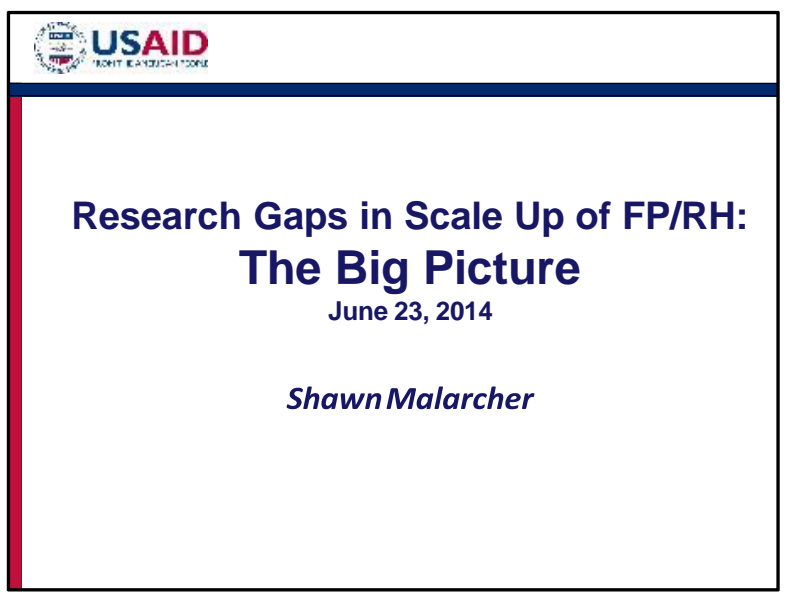

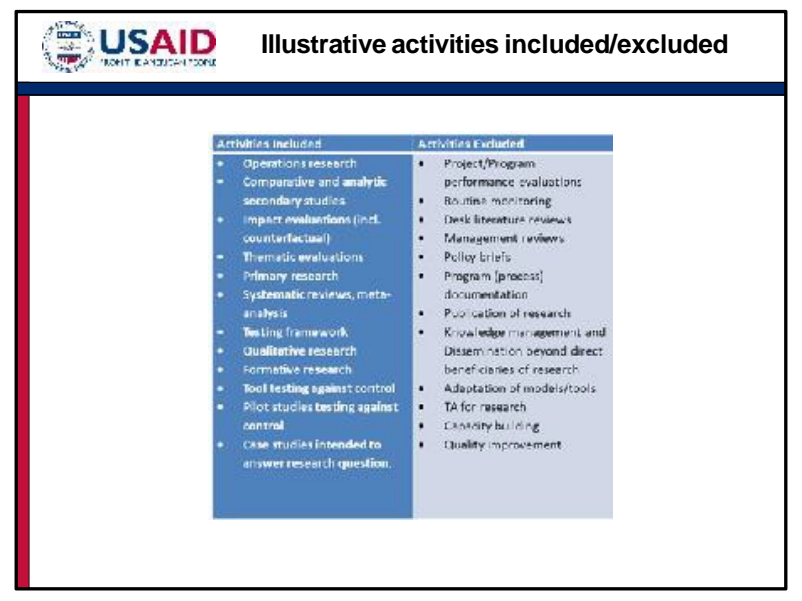

\section{USAID PRH Research Strategy}

Objectives:

- An improved understanding of our current investments in research

- A process for improving the quality of research supported by the Office

- A prioritized list of researchable questions

Defining "research":

Systematic investigation of a well-defined problem, intended to produce knowledge that will offer solutions to specific development challenges. This includes research, experimentation, and product development in all fields. It includes qualitative and quantitative data collection. (based on

Research methods and measure
- Type of research question: validation, research
method refinement
Formative - assessment or formative research to identify
the nature, determinants, or extent of a public health problem,
and opportunities to address that problem; social and behavioral
science research that advances knowledge of determinants and
consequences of health behavior.
- Type of research question: Describe user
dynamics, fertility determinants, or fertility
consequences

\section{USAID Research Typology Continued}

Contraceptive Technologies - applied biomedical research that develops new or improves existing health products/technologies

- Type of research question: pre-clinical, safety, method efficacy, user perspective, delivery mechanics, market analysis

Intervention (health system) or Intervention (outside health system) - operations research and program health services research that improve delivery of information and services; and develops new or improves existing tools and approaches to change health-related behaviors at individual, community, and institutional levels

- Type of research question: acceptability, feasibility, cost, costeffectiveness, market studies

\section{USAID Research Typology Continued}

Research on scale-up - introduction or adaptation research that facilitates the adoption/uptake or effectiveness in a local context of a tool, approach, or intervention in the context of scaling up or regular use in public health practice.

- Type of research question: demonstration, adaptation, scale-up 


USAID Examples of research questions for
scale-up
- Which adaptation models led to greater
uptake and use at the field-level and why?
What "does it take" to scale up X intervention?
Should replication studies fit here, even if they
use the same methods as an intervention study?
(ie. task sharing)

USAID For consideration
What is needed to support effective scale-
up?
What role does centrally-funded research
have in supporting these efforts?
- Are results from scale-up research
generalizable or are they context specific?

\begin{tabular}{c}
\hline USAID \\
Thank You \\
Questions/Discussion \\
\hline
\end{tabular}



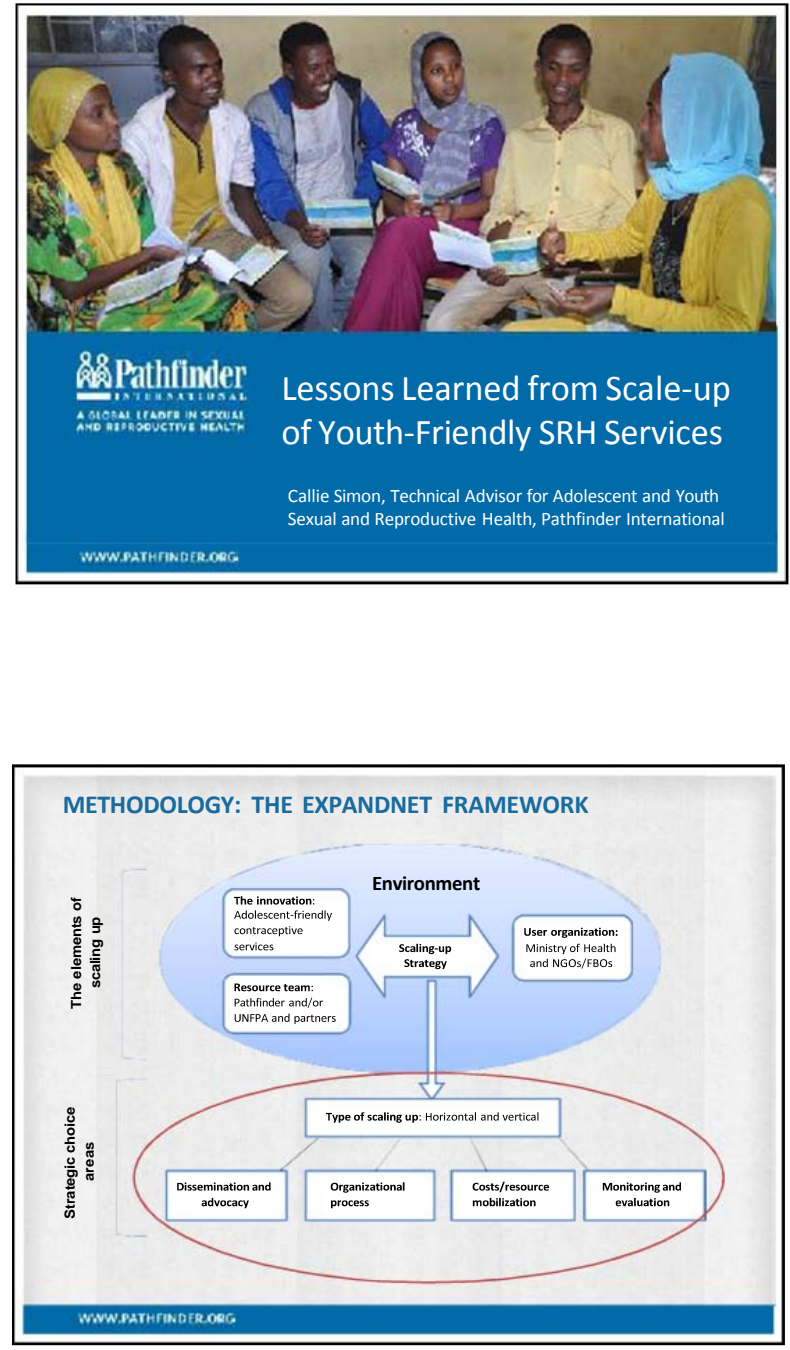

\begin{tabular}{|c|c|c|c|}
\hline \multicolumn{4}{|c|}{ Ethiopia (RH/FP Project and Integrated Family Health Program ) } \\
\hline Phase 1 & Phase 2 & Phase 3 & Phase 4 \\
\hline 2005-2007 & 2008-2009 & 2010-2011 & 2012-2014 \\
\hline $\begin{array}{l}\text { Site ready assessment; } \\
\text { learning trip to } \\
\text { Mozambique; consensus } \\
\text { building; pilot in } 20 \text { YFS } \\
\text { sites in } 4 \text { regions }\end{array}$ & $\begin{array}{l}\text { Expansion to } 64 \\
\text { YFS sites in } 4 \\
\text { regions }\end{array}$ & $\begin{array}{l}\text { Expansion to } 115 \\
\text { YFS sites in } 6 \\
\text { regions }\end{array}$ & $\begin{array}{l}\text { Expansion to } 163 \text { YFS sites } \\
\text { in } 6 \text { regions; transition to } \\
\text { government }\end{array}$ \\
\hline \multicolumn{4}{|c|}{ Ghana (African Youth Alliance) } \\
\hline Phase 1 & Phase 2 & & Phase 3 \\
\hline 2000-2001 & 2002 & & 2003-2004 \\
\hline $\begin{array}{l}\text { Consensus building; } \\
\text { stakeholder buy-in }\end{array}$ & \multicolumn{2}{|c|}{ YFS introduced in 19 sites in 3 regions } & $\begin{array}{l}\text { Expansion to } 65 \text { YFS sites } \\
\text { in } 5 \text { regions }\end{array}$ \\
\hline
\end{tabular}

INNOVATION: YOUTH-FRIENDLY SERVICES

\section{Characteristics of the innovation}

- Package of SRH services offered by trained providers through public sector facilities and (depending on country) through private facilities, workplace programs, and CBD.

- Emphasis on privacy, confidentiality, respectful treatment

- Accompanied by demand generation and enabling environment activities

- Emphasized youth participation and leadership in program design and implementation

\section{SCALE UP APPROACH}

ВОTH vertical and horizontal scale up approaches were pursuedcontributing to the sustainable scale-up of YFS

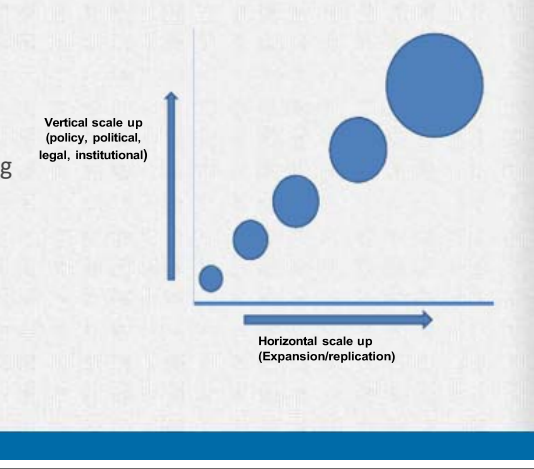

\begin{tabular}{|c|c|c|c|}
\hline \multicolumn{4}{|l|}{ Mozambique (Geração Biz) } \\
\hline Phase 1 & Phase 2 & Phase 3 & Phase 4 \\
\hline $1999-2000$ & 2000-2005 & 2005-2008 & 2008-2012 \\
\hline $\begin{array}{l}\text { Consensus building; needs } \\
\text { assessments; pilot introduced } \\
\text { in } 12 \text { sites in } 2 \text { provinces }\end{array}$ & $\begin{array}{l}\text { Expansion to } 83 \\
\text { sites in } 8 \\
\text { provinces }\end{array}$ & $\begin{array}{l}\text { Expansion to } 244 \\
\text { YFS sites in all } 11 \\
\text { provinces }\end{array}$ & $\begin{array}{l}\text { System strengthening \& } \\
\text { capacity building for transition } \\
\text { to government; continued } \\
\text { multisectoral coordination }\end{array}$ \\
\hline \multicolumn{4}{|l|}{ Tanzania (African Youth Alliance) } \\
\hline Phase 1 & Phase 2 & & Phase 3 \\
\hline 2001 & 2002 & & 2003-2004 \\
\hline $\begin{array}{l}\text { Consensus building; } \\
\text { stakeholder buy-in }\end{array}$ & 11 YFS sites introd & duced in 4 regions & $\begin{array}{l}\text { Expansion to } 58 \text { YFS sites in } 8 \\
\text { regions }\end{array}$ \\
\hline \multicolumn{4}{|c|}{ Vietnam (Reproductive Health Projects) } \\
\hline Phase 1 & Phase 2 & & Phase 3 \\
\hline 2004-2006 & 2007-2008 & & 2009-2011 \\
\hline $\begin{array}{l}\text { Consensus building; learning } \\
\text { trip to Thailand; pilot of } 5 \text { YFS } \\
\text { sites in } 3 \text { provinces }\end{array}$ & $\begin{array}{l}\text { Expansion to } 19 \mathrm{Y} \\
\text { provinces }\end{array}$ & YFS sites in 7 & $\begin{array}{l}\text { Expansion to } 28 \text { YFS sites in } 17 \\
\text { provinces }\end{array}$ \\
\hline
\end{tabular}




\section{SCALE-UP APPROACH: VERTICAL SCALE}

- Supported development of national strategies, policies, guidelines, and standards

- Institutionalized "tools" for implementing innovation (national curricula, supervision tools, monitoring tools)

- Capacity building of government at different levels to implement, supervise, and monitor YFS (context of decentralization)

- Supported inclusion of YFS into training and supervision systems

- Advocacy and capacity building for YFS inclusion in national budgets and regional/district workplans and budgets

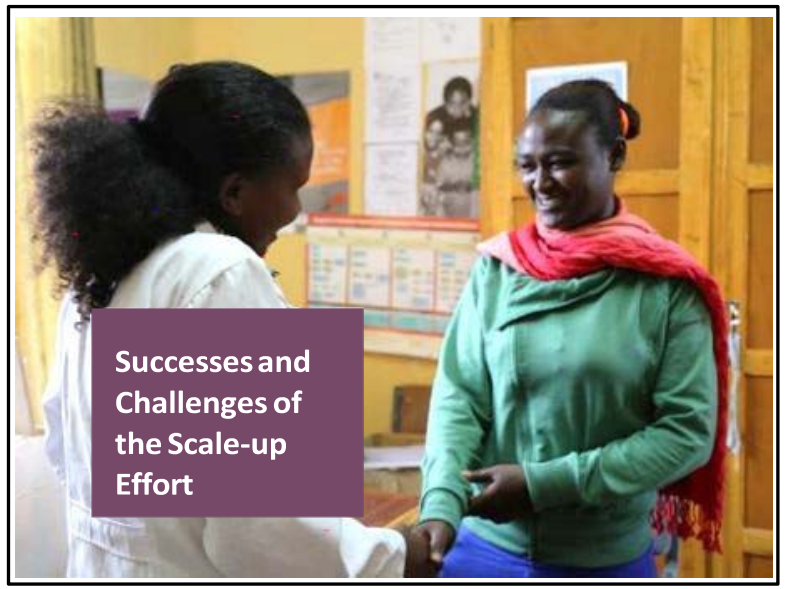

\begin{tabular}{|l|l|l||}
\hline \multicolumn{3}{|c|}{ RESULTS OF THE SCALE-UP EFFORT } \\
\hline $\begin{array}{l}\text { Country } \\
\text { Timeframe }\end{array}$ & $\begin{array}{l}\text { Horizontal scale: } \\
\text { Service delivery } \\
\text { points (SDPs) }\end{array}$ & $\begin{array}{l}\text { Vertical scale: } \\
\text { Types of policies, guidelines, and systems } \\
\text { influenced by intervention }\end{array}$ \\
\hline Mozambique & $\begin{array}{l}\text { 244 AFHS sites in 119 } \\
\text { districts in all } \\
\text { provinces (11) }\end{array}$ & $\begin{array}{l}\text { National training curriculum; National ASRH } \\
\text { Guidelines; MOYS Outreach Strategy for out-of- } \\
\text { school youth; National AIDS Strategic Plan; MOE } \\
\text { National Strategy for AFHS and school-based } \\
\text { curriculum with SRH; inclusion of YFS in 2010 } \\
\text { government 5 year plan; provincial directorates } \\
\text { include YFS in budget; revision of HMIS }\end{array}$ \\
\hline Tanzania & $\begin{array}{l}58 \text { sites in 11 districts } \\
\text { in } 8 \text { out of 30 regions }\end{array}$ & $\begin{array}{l}\text { National AFHS training curriculum; National } \\
\text { Adolescent Health and Development Strategy; ASRH } \\
\text { priority area in Poverty Reduction Strategy; ASRH in } \\
\text { national and district plans and budgets }\end{array}$ \\
\hline $\begin{array}{l}\text { Viet Nam } \\
\text { 2004-2010 }\end{array}$ & $\begin{array}{l}28 \text { sites in 17 out of } \\
63 \text { provinces }\end{array}$ & $\begin{array}{l}\text { ASRH in National Standards and Guidelines; National } \\
\text { Strategy on Youth Development; National AFHS } \\
\text { Guidelines; national training curriculum and tools }\end{array}$ \\
\hline
\end{tabular}

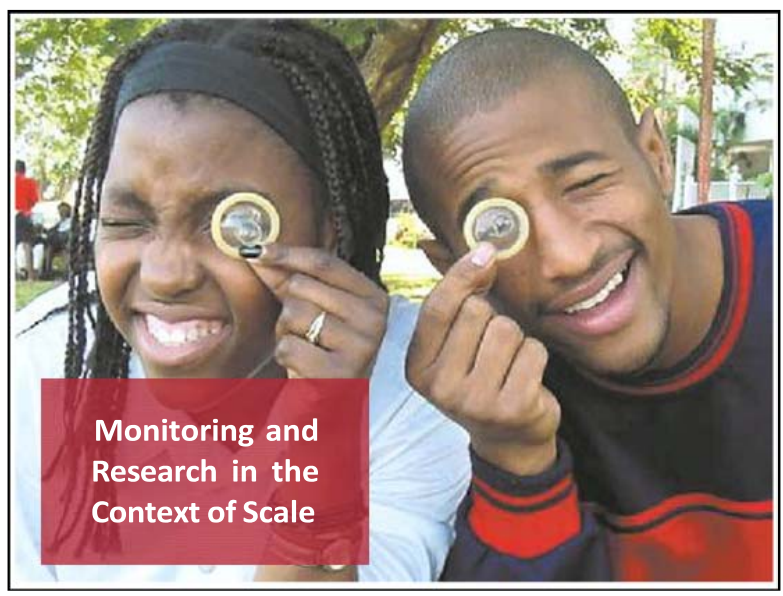

\section{CHALLENGES}

- Reliance on external and time-bound funding to catalyze scale up of

- Lack of international donor commitment to adolescents

- Innovation didn't reach the most vulnerable adolescents (at scale)

- The need to strengthen broader health system (e.g., commodity security, pre- and in-service FP training, HMIS data disaggregated by age and method) before adding on adolescent-specific components

- High turn over of trained providers and peer educators a challenge to sustainability

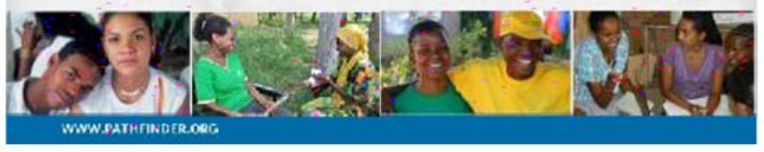

RESULTS OF THE SCALE-UP EFFORT

\begin{tabular}{|l|l|l|}
\hline $\begin{array}{l}\text { Country } \\
\text { Timeframe }\end{array}$ & $\begin{array}{l}\text { Horizontal scale: } \\
\text { Service delivery points } \\
\text { (SDPs) }\end{array}$ & $\begin{array}{l}\text { Vertical scale: } \\
\text { Types of policies, guidelines, and systems } \\
\text { developed/adapted to include YFS }\end{array}$ \\
\hline $\begin{array}{l}\text { Ethiopia } \\
\text { present }\end{array}$ & $\begin{array}{l}163 \text { SDPs in } 6 \text { of } 9 \\
\text { regions }\end{array}$ & $\begin{array}{l}\text { National ASRH Strategy; National Standards } \\
\text { and Minimum Service Delivery Package; } \\
\text { National Planning, Implementation, and } \\
\text { Evaluation Tools; YFS in national, regional and } \\
\text { district workplans and budgets }\end{array}$ \\
\hline $\begin{array}{l}\text { Ghana } \\
\text { 2000-2005 }\end{array}$ & $\begin{array}{l}65 \text { SDPs in 20 districts in } 5 \\
\text { out of 10 regions }\end{array}$ & $\begin{array}{l}\text { National ASRH Guidelines and Policy; national } \\
\text { in-service and preservice training curriculum; } \\
\text { revision of National HIV/AIDS Policy and } \\
\text { School Health Policy and Action Plan; HMIS } \\
\text { age-disaggregation; YFS in district workplans } \\
\text { and budgets; YFS integrated into private } \\
\text { sector/NGO service delivery systems }\end{array}$ \\
\hline
\end{tabular}

1




\section{INFLUENCE OF MONITORING ON SCALE-UP PROCESS AND PERFORMANCE AT SCALE}

- Lack of age and sex-disaggregated data collection within national HMIS required parallel program MIS

- Established system for using data for decision-making to improve service access and quality

- Monitored service quality (e.g., method mix; client satisfaction) using mystery clients and client exit interviews and service observation to ensure fidelity during scale up

- Need to emphasize monitoring vertical scale-up processes (e.g., capacity building, advocacy, policy and guideline development)

\section{INFLUENCE OF RESEARCH ON THE SCALE-UP PROCESS AND PROGRAM PERFORMANCE AT SCALE}

- In Vietnam, evaluation of pilot phase informed selection of type of facility in which to scale YFS

- OR in Mozambique to address recruitment, retention and performance of female peer educators during program scale up

- Study in Ethiopia on expanding access to LARC to ensure greater method mix

\section{AREAS FOR FURTHER RESEARCH RELATED TO SCALE AND SUSTAINABILITY}

- Greater understanding of the most essential features of YFS to further streamline the innovation

- Feasibility and implications of scaling-up non-facility based service delivery modalities

- Effective strategies to reach vulnerable and harder to reach adolescent populations at scale

- Strategies to shift provider behavior and attitudes, beyond in-service training modalities, that can be done at scale

- Implementation research around implementation processes that facilitate scale, not just evaluation of effectiveness

- Factors that increase or hinder sustainability of scale up

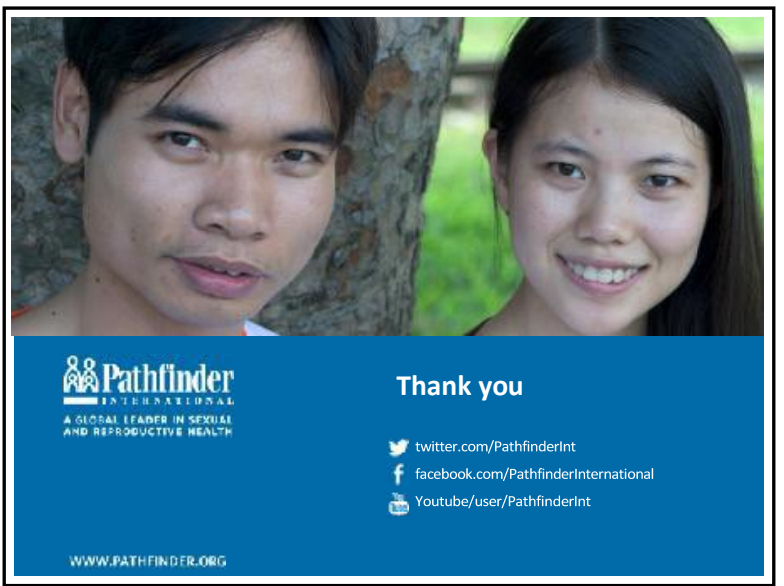

WWW.PATHFINDER.ORG

\begin{tabular}{|c|c|c|c|}
\hline \multicolumn{4}{|l|}{ RESULTS } \\
\hline \multicolumn{4}{|c|}{$\begin{array}{l}\text { Demographic characteristics of Implanon acceptors from Pathfinder study and } \\
\text { acceptors of other methods compared to rural implant users (EDHS 2011) }\end{array}$} \\
\hline Age in Years & $\begin{array}{c}\text { Implanon Acceptors } \\
\text { Pathfinder Study } \\
(\%) \\
(n=5,777)\end{array}$ & $\begin{array}{l}\text { Other Method } \\
\text { Acceptors } \\
(\%) \\
(n=225)\end{array}$ & $\begin{array}{c}\text { Implant users DHS } \\
2011 \text { - rural only } \\
\begin{array}{c}(\%) \\
(n=186)\end{array}\end{array}$ \\
\hline $15-19$ & 4.9 & 10.2 & 5.4 \\
\hline 20-24 & 20.1 & 29.3 & 7.5 \\
\hline $25-29$ & 31.7 & 28.0 & 25.8 \\
\hline $30-34$ & 23.7 & 13.3 & 18.3 \\
\hline $35-39$ & 14.3 & 13.3 & 20.4 \\
\hline $40-44$ & 4.2 & 5.3 & 16.7 \\
\hline $45-49$ & 1.1 & 0.4 & 5.9 \\
\hline Mean Age (SD) & $28.3(6.0)$ & $26.8(6.6)$ & $32.7(7.8)$ \\
\hline \multicolumn{4}{|c|}{$\begin{array}{l}\text { Mengistu et. al. Addressing Unmet Need for Long Acting Family Planning in Ethiopia: Uptake of Implanor } \\
\text { and Characteristics of Users. Intemational Journal of Gynecology and Obstetrics - September } 2013\end{array}$} \\
\hline
\end{tabular}

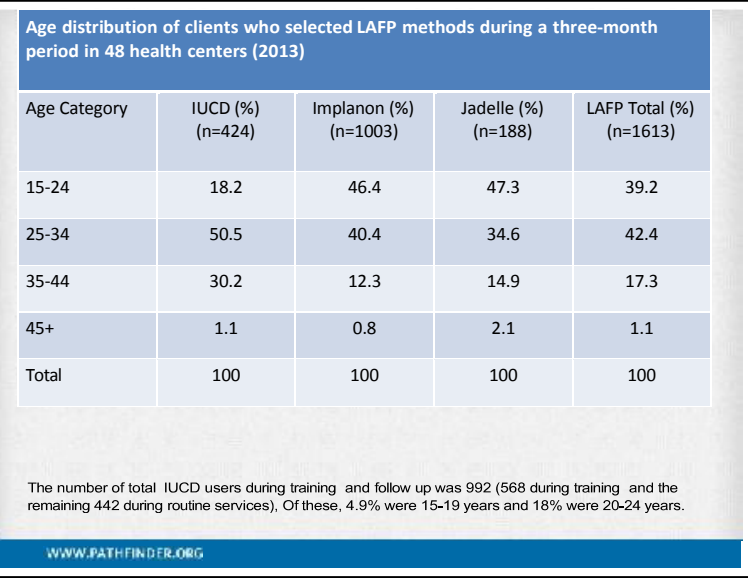




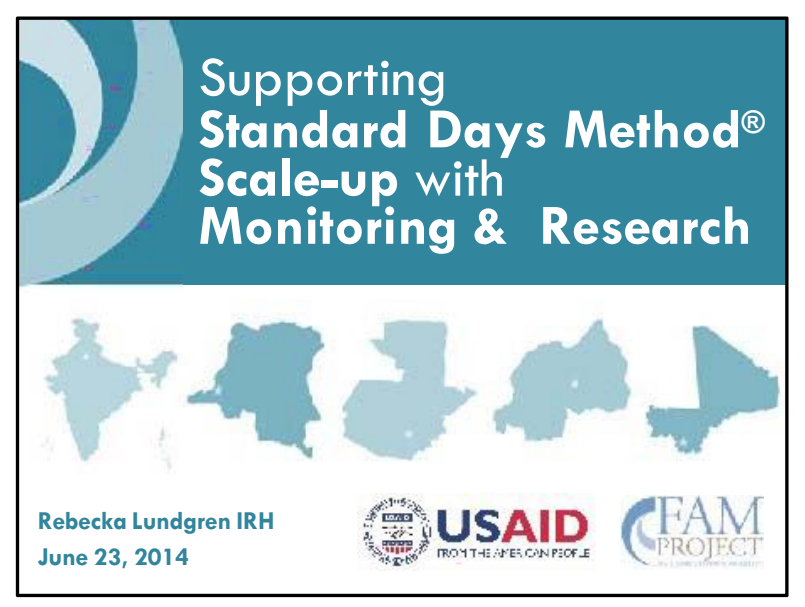

\section{STANDARD DAYS METHOD SCALE UP CASE STUDY (2007-2012)}

- Prospective, multi-site, comparative study of process and outcomes of scaling up a family planning innovation

- Democratic Republic of Congo, Guatemala, India (Jharkhand), Mali, Rwanda
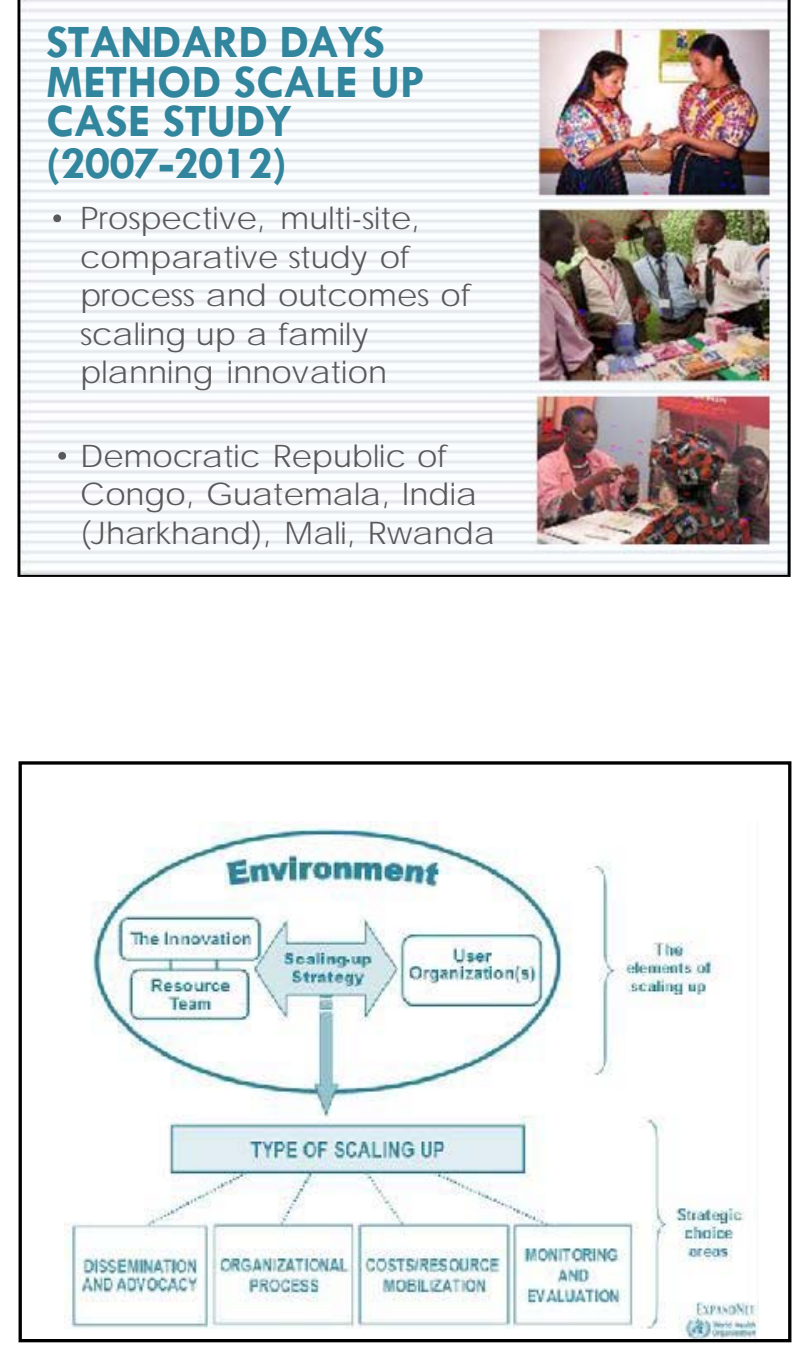
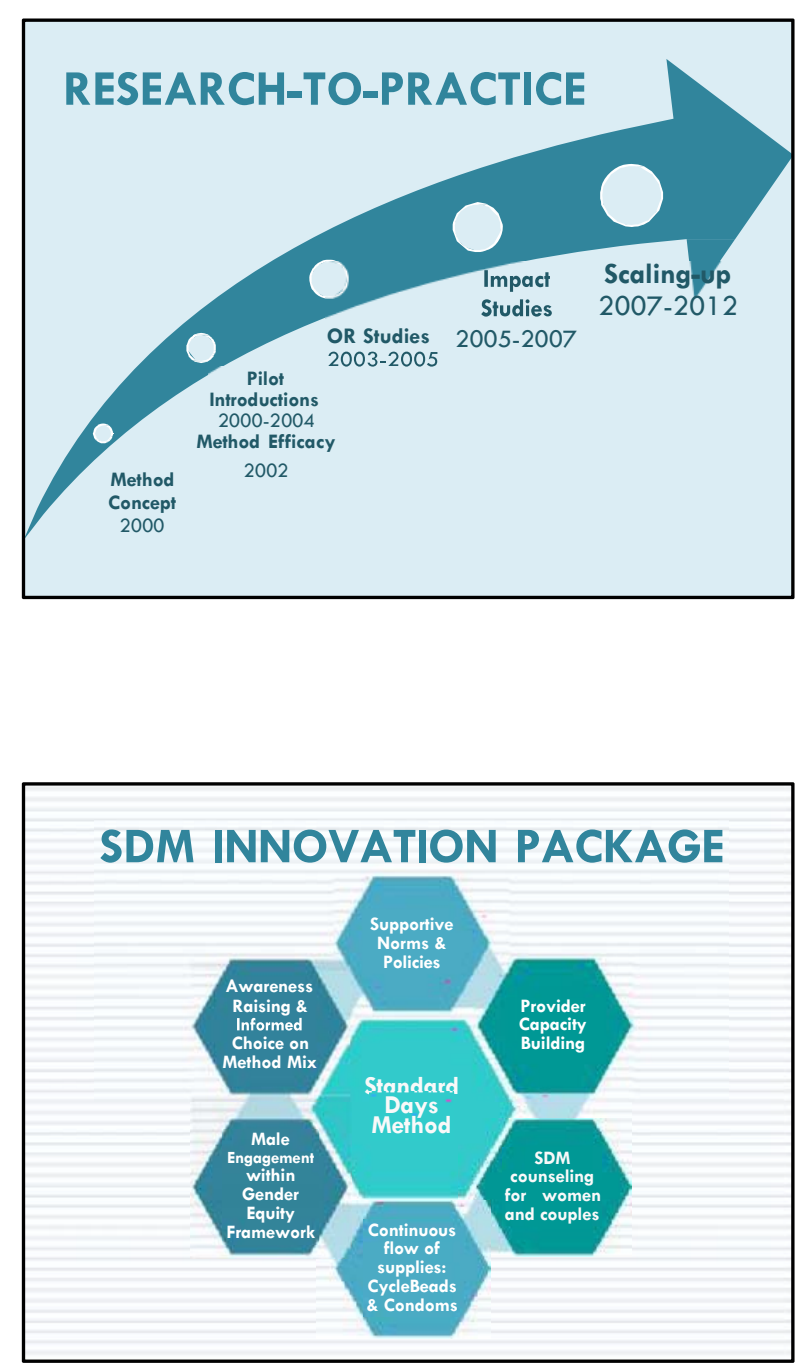

\section{SCALE-UP APPROACH}

- Well-defined innovation package

- Systems focus

- Engaging stakeholders and building strategic partnerships

- Participatory approach

- Systematic use of evidence for decisionmaking

- Focus on sustainability 


\section{AFTER 5+ YEARS: GOALS \& ACHIEVEMENTS}

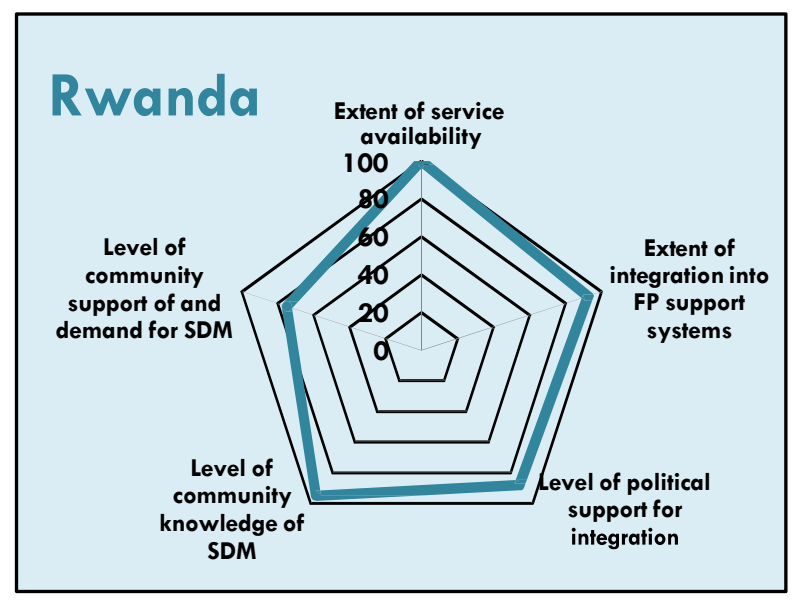

\begin{tabular}{|c|c|c|c|c|c|}
\hline $\begin{array}{l}\text { SERVICE } \\
\text { EXPANSION } \\
\text { INDICATOR }\end{array}$ & DRC & GUATEMALA & JHARKHAND & MALI & RWANDA \\
\hline $\begin{array}{l}\text { \# OF SERVICE } \\
\text { DELIVERY POINTS } \\
\text { OFFERINGSDM }\end{array}$ & 300 & 305 & 1,900 & 1,273 & $\begin{array}{c}717 \text { (PUBLIC, } \\
\text { PRIVATE) }\end{array}$ \\
\hline COVERAGE & $\begin{array}{l}58 \% \text { OF HEALTH } \\
\text { ZONES }\end{array}$ & $\begin{array}{l}99 \% \text { OF TARGET } \\
\text { SDPs } \\
3 \text { DEPARTMENTS } \\
\text { (1/6 OF } \\
\text { COUNTRY) }\end{array}$ & $\begin{array}{ll}\cdot & 90 \% \text { OF TARGET } \\
& \text { SDPs } \\
\text { - } & 11 \text { OF } 24 \\
& \text { JHARKHAND } \\
\text { DISTRICTS }\end{array}$ & $\begin{array}{ll}\text { - } & 88 \% \text { OF } \\
& \text { SDPS } \\
\text { - } & \text { ALL } 8 \\
\text { REGIONS } & \text { Ren } \\
\end{array}$ & $\begin{array}{l}\text { - All } 30 \\
\text { DISTRICTS }\end{array}$ \\
\hline $\begin{array}{c}\text { \# OF } \\
\text { ORGANIZATIONS } \\
\text { ON RESOURCE } \\
\text { TEAM }\end{array}$ & 27 & 14 & 3 & 19 & 7 \\
\hline $\begin{array}{l}\text { EXPANSION } \\
\text { CATEGORY }\end{array}$ & $\begin{array}{l}\text { POST-CONFICT } \\
\text { FP } \\
\text { REVITALIZATION }\end{array}$ & \multicolumn{2}{|c|}{$\begin{array}{l}\text { UMITED GOALS ON SCALE-UP; } \\
\text { FOUNDATION LAID FOR NATIONWIDE } \\
\text { FUTURE }\end{array}$} & \multicolumn{2}{|c|}{ NEAR-NATIONAL SCALE-UP } \\
\hline SERV & CE & $\Delta \| \Delta$ & ILITY & RESU & LTS \\
\hline
\end{tabular}

\section{SCALE-UP GOALS IN RWANDA \\ - Availability of SDM in $95 \%$ of public and private health \\ facilities that offer FP and in all community- based services \\ - Instifutionalization of SDM into FP support systems

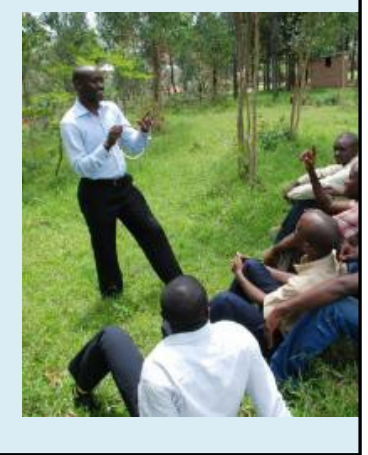

\section{SDM AVAILABILITY IN RWANDA} 2007 \& 2012
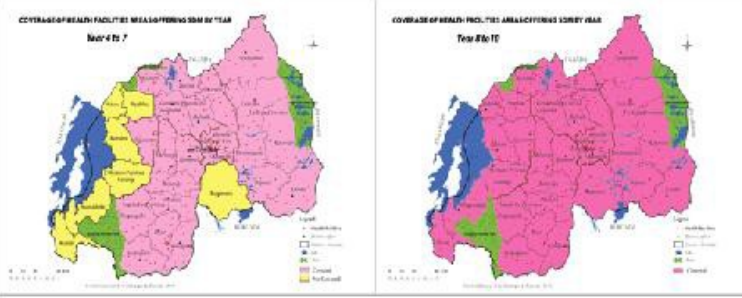

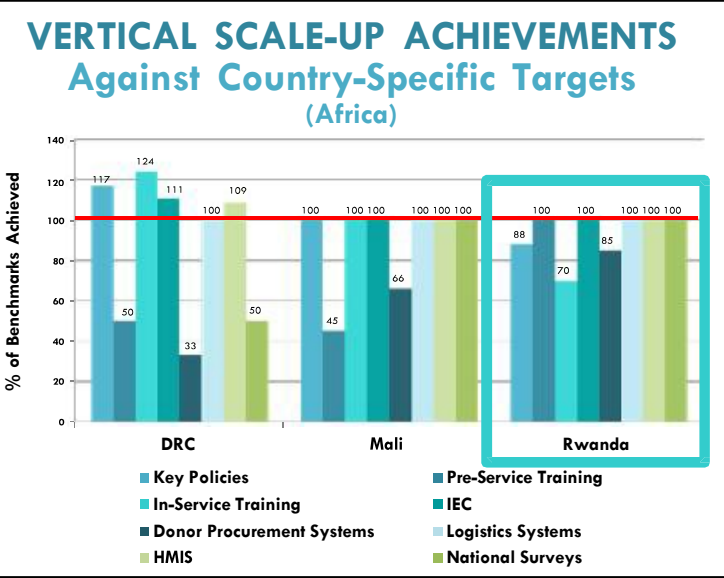



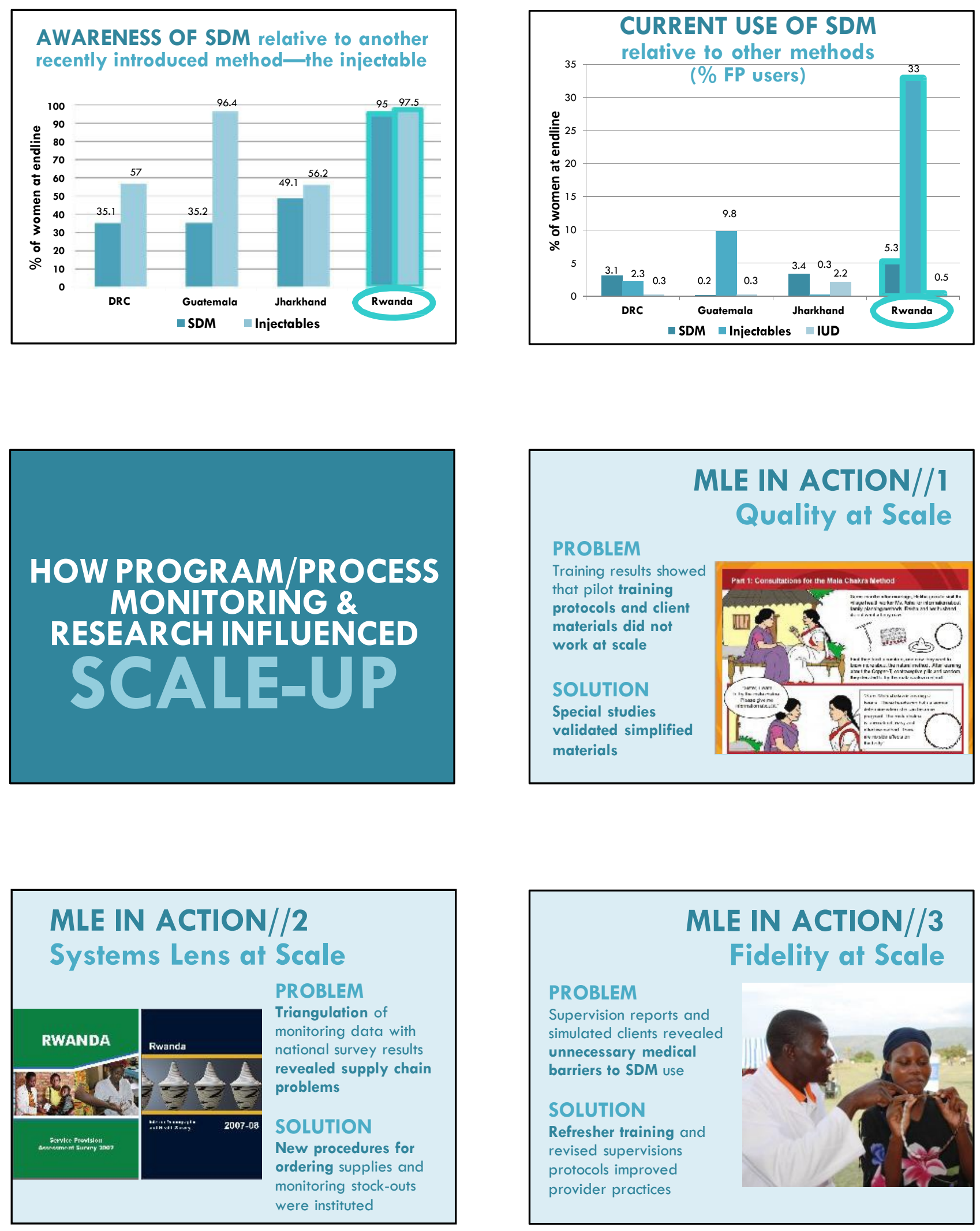

\section{MLE IN ACTION//3 Fidelity at Scalle}

PROBLEM

Supervision reports and simulated clients revealed unnecessary medical barriers to SDM use

\section{SOLUTION}

Refresher training and revised supervisions protocols improved provider practices

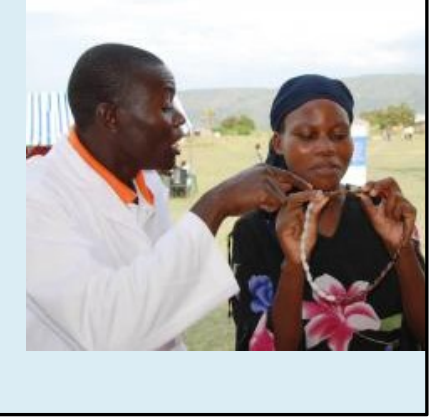



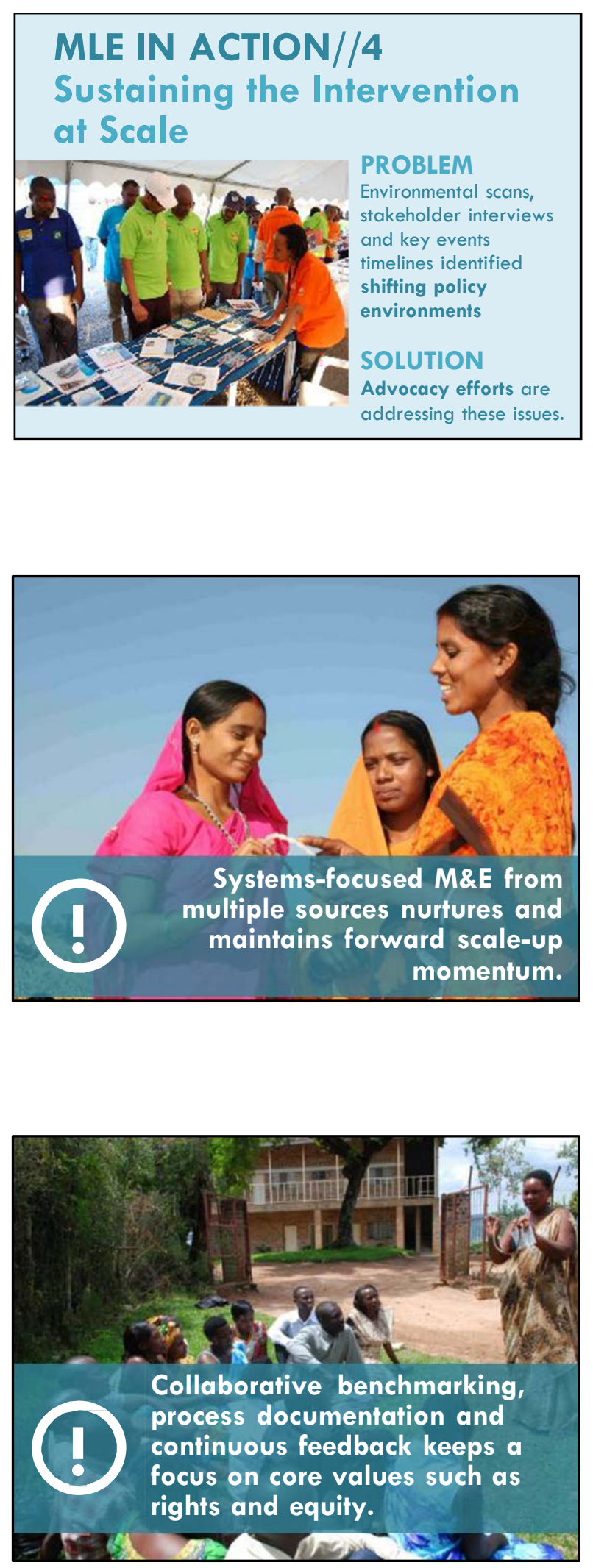

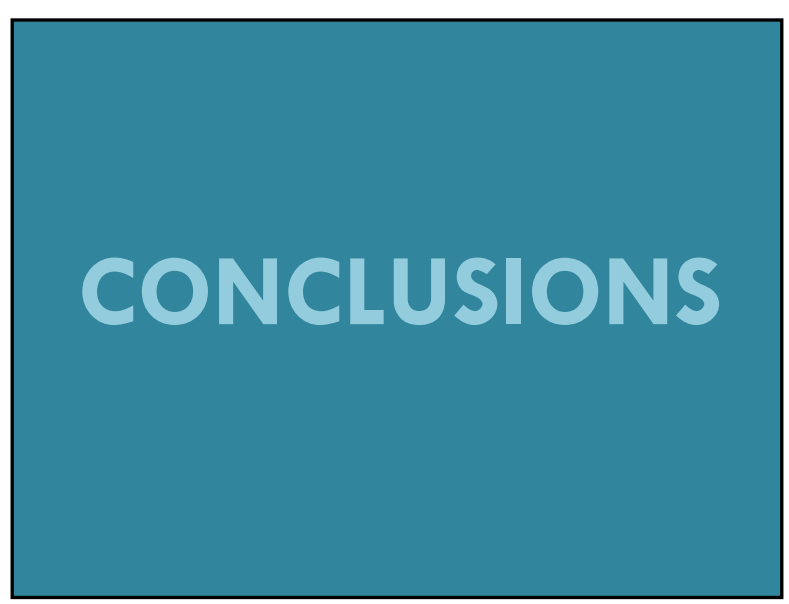

Encourages concurrent work along vertical and horizontal axes of scale-up

Results in participatory engagement and coordinated action

Helps resource team monitor and respond to environmental forces

\section{HOW BENEETS}

\begin{tabular}{|l|}
\hline $\begin{array}{l}\text { Prioritized approaches to reach } \\
\text { underserved }\end{array}$ \\
$\begin{array}{l}\text { Expanded access beyond facility- } \\
\text { based services }\end{array}$ \\
\hline Engaged new stakeholders \\
\hline Participatory MLE amplified client voices \\
\hline HOW SCALE-UP BENEEITS \\
\hline
\end{tabular}




\section{WHAT CHALLENGES/ KNOWLEDCE CAPS COULD BE ADDRESSED}

GAP 1: Defining sustainable scale-up Q: In relation to what? How much is enough? What criteria define sustainability?

\section{GAP 2: Levers of scale up}

Q: How does gender influence scale up? How should scale up take into account gender?

\section{GAP 3: Active implementation}

Q: What are effective approaches for TA and skill transfer?
GAP 4: Policy barriers to scale-up

Q: What prevents some international organizations from integrating SDM? How does global donor/TA community influence scale up?

GAP 5: Environmental influences on scale up and sustainability levels

Q: How do you effectively track policy changes?

GAP 6: Equity and scale up

\section{G)(SD GIOORAI HFAITH: SCIFNCF AND PRACTICF}

\section{ORIGINAL ARTICLE}

Systems approach to monitoring and evaluation guides scale up of the Standard Days Method of family planning in Rwanda

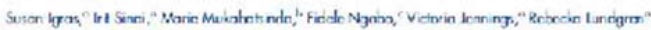

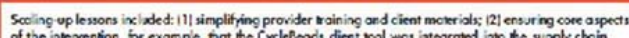

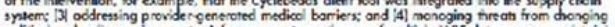

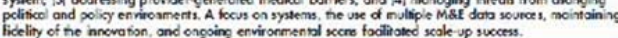

ABSTRACT

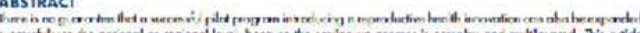

Open Access download available at www.irh.org

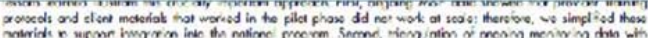

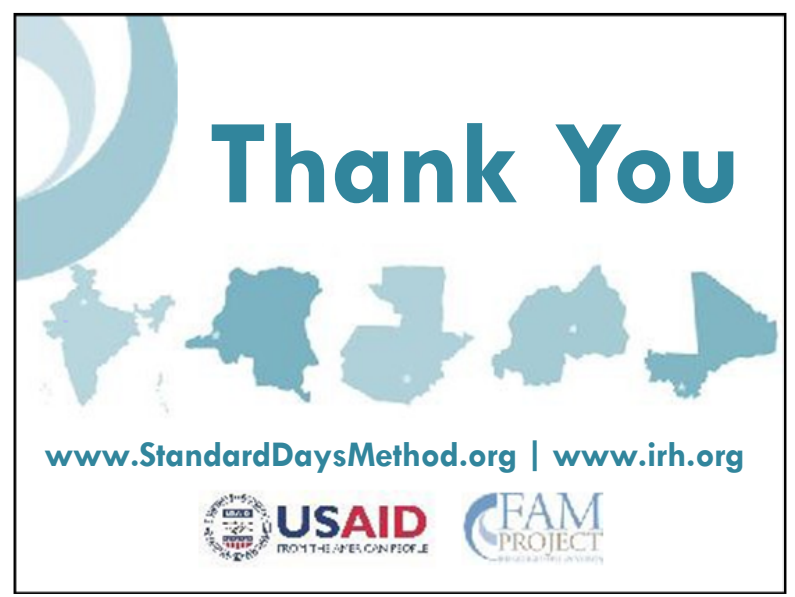



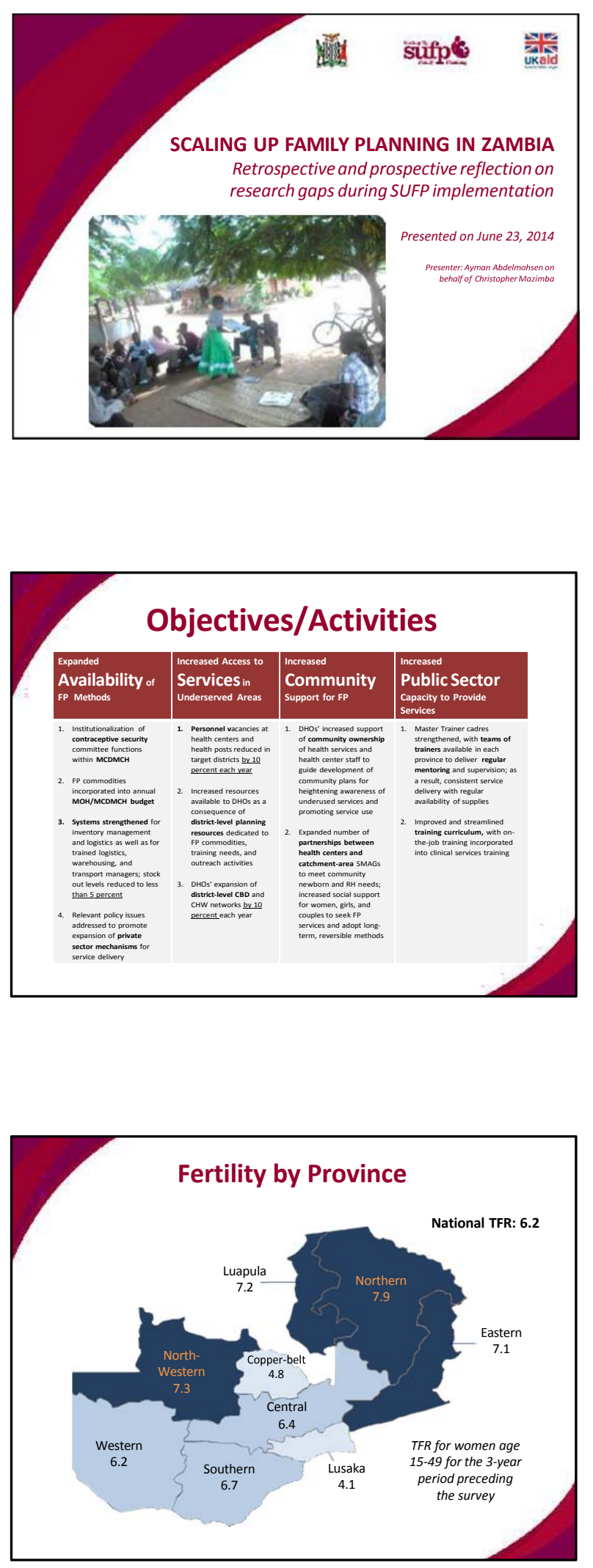

\section{Project Background}

- Four year project (currently in Year 3)

- Funded by DFID under RH Framework

- Key Partners: PPAZ, UNFPA, ACNM, ZEHRP, Imperial health Sciences(IHS)

- Overarching strategy is to work with existing public sector institutions to increase FP use

- Focused on rural and hard-to-reach areas of Zambia
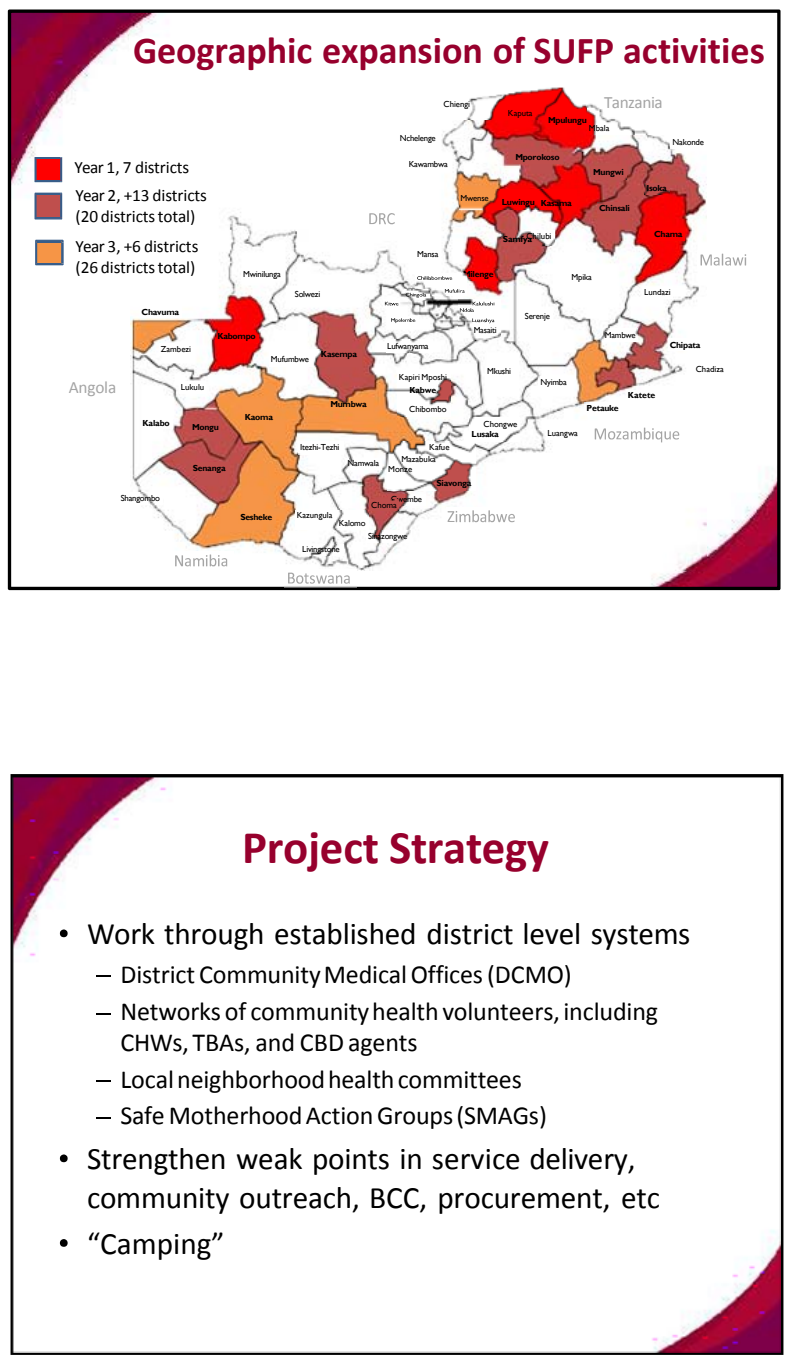


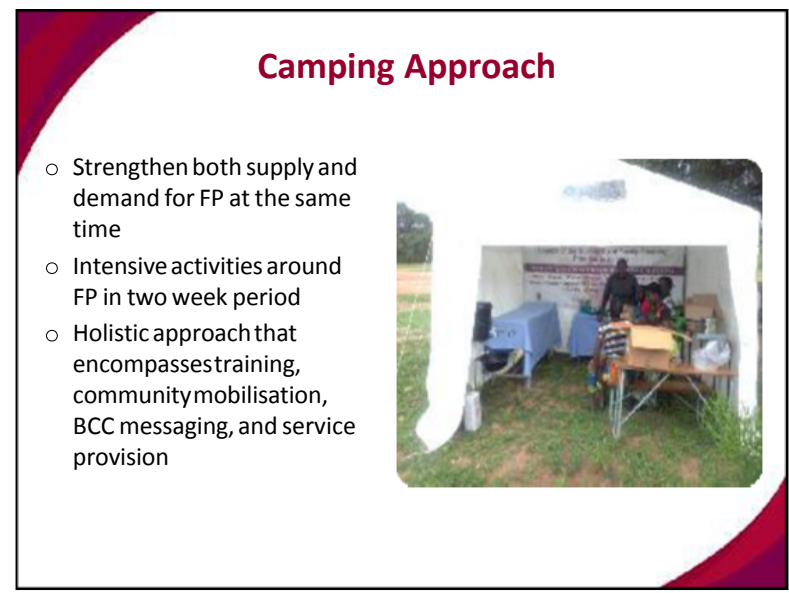

\section{Year 1 Pilot District Activities}

- Rapid FP assessment

- Community mapping

- BCC assessment

- Baseline Survey

- Camping

- CBDs trained from existing cadres of volunteers

- Orientation workshops for community groups, youth groups, and influential traditional and religious leaders

- Drama groups, radio messages, jingles, and TV documentaries for sensitization

- Trained public sector facilities to provide LTRM

\section{Project Startup}

- National level assessment of RH commodities and supply chain management

- Selection of pilot districts and rollout of activities
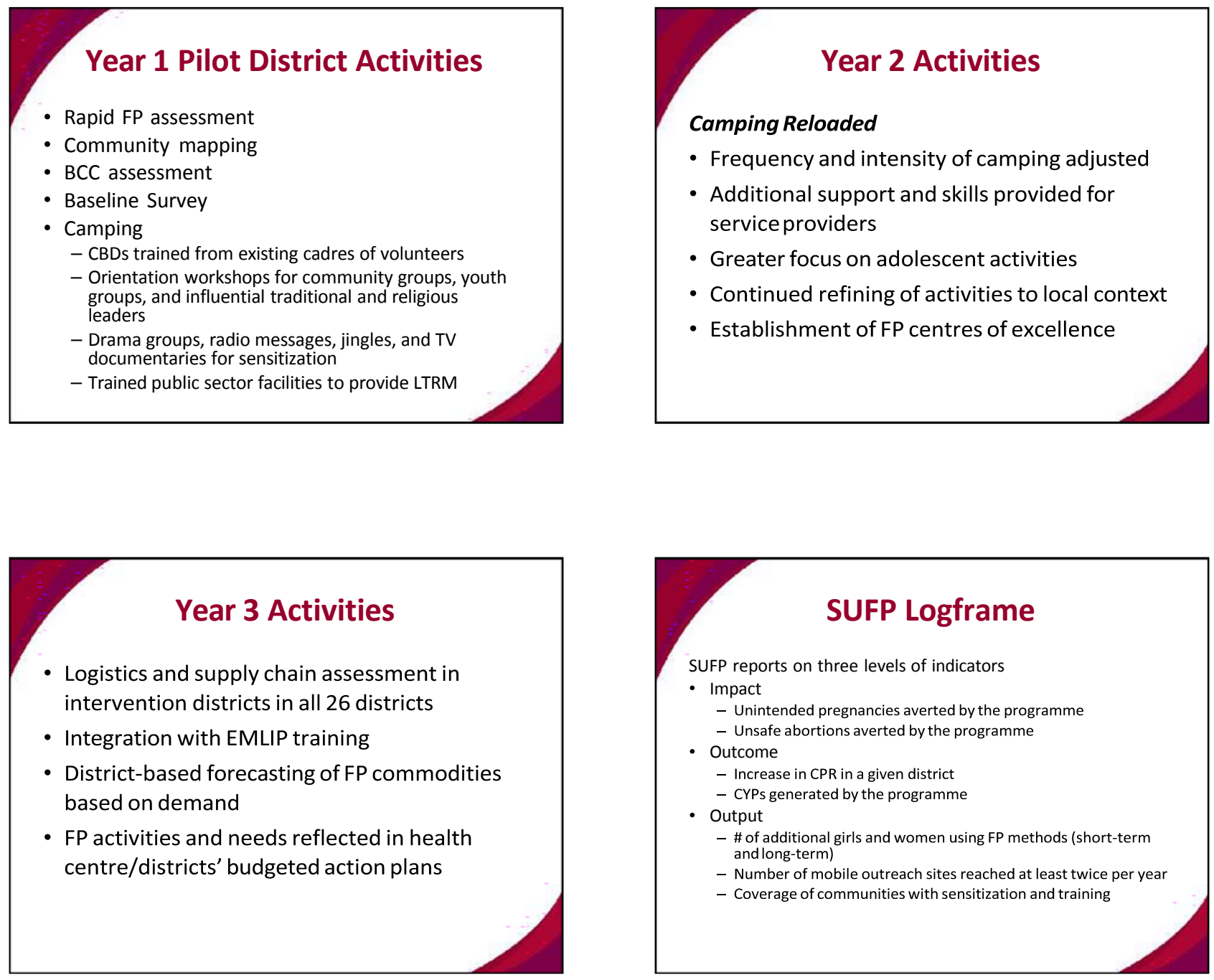


\section{M\&E and Reporting on Logframe}

- Use routine monitoring data captured from health facility database

- Support data collection for Reproductive Health Commodity Security Status

- SUFP holds regular M\&E orientation meetings with GRZ staff, SUFP field staff and CBDs

- Stakeholder Dissemination meetings with key partners to share best practices

\section{Challenges \& Lessons Learned}

- Long distances coupled with bad roads (need for FP services to be as close to the families as possible)

- Logistical and human resource challenges to carry out outreach activities

- District teams need continuous support to maintain morale

- On-site monitoring and feedback is very effective

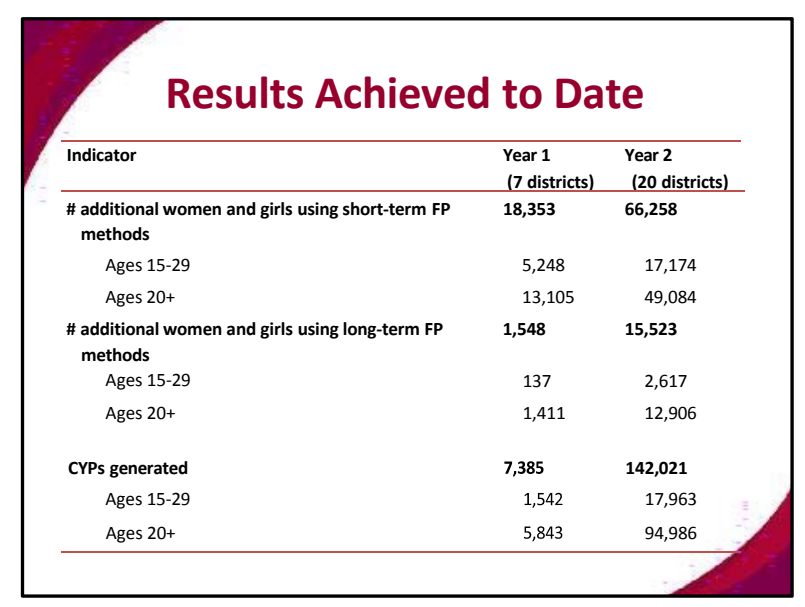

\section{Research Gaps - Retrospective}

- Identification of the scalability of the camping approach before implementation

- More focused needs assessment of youth in each district prior to youth interventions

\section{Research Needs}

- Can changes in FP indicators be attributed to SUFP activities?

-What does government need in order to take over project after SUFP ends?

- How effective are the different models of camping? Which is the most effective?

-What is the cost of the various models of camping?

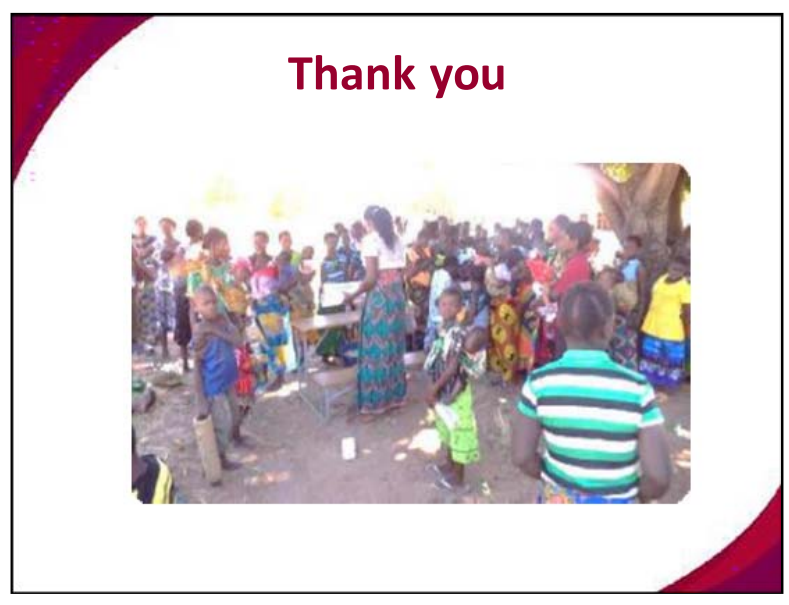




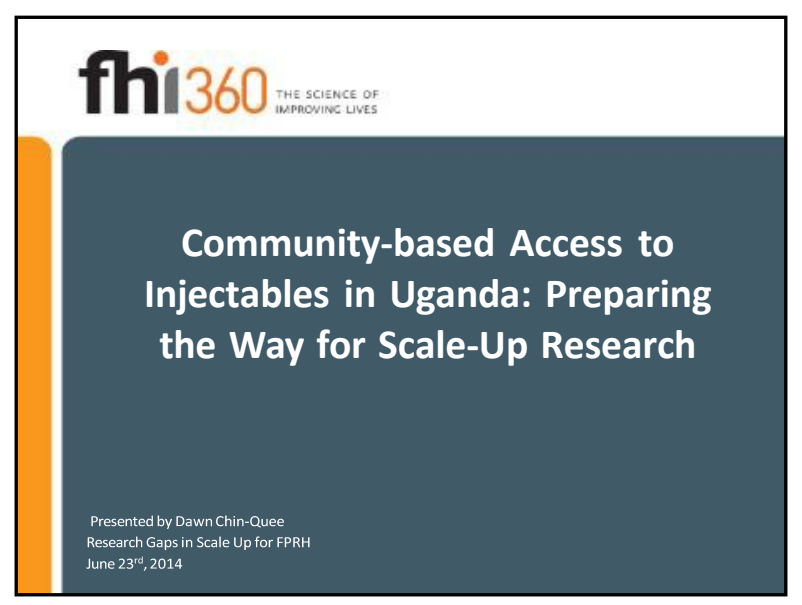

Uganda: Sub Saharan Africa's Pioneer in CBA2I

FHI 360 collaborated with Save the Children, 2003 to 2005

Feasibility and safety tested in Nakasangola

In private sector

Save the Children: Nakaseke and Luwero districts

Conservation through Public Health: Kanungu district

- Minnesota Int'I Health Volunteers: Mubende district

In public sector

Advocacy literature disseminated to all districts

Selected Busia and Bugiri for replication of CBA2I

fhi 360

THE SCIENCE OF IMPROVING LIVES
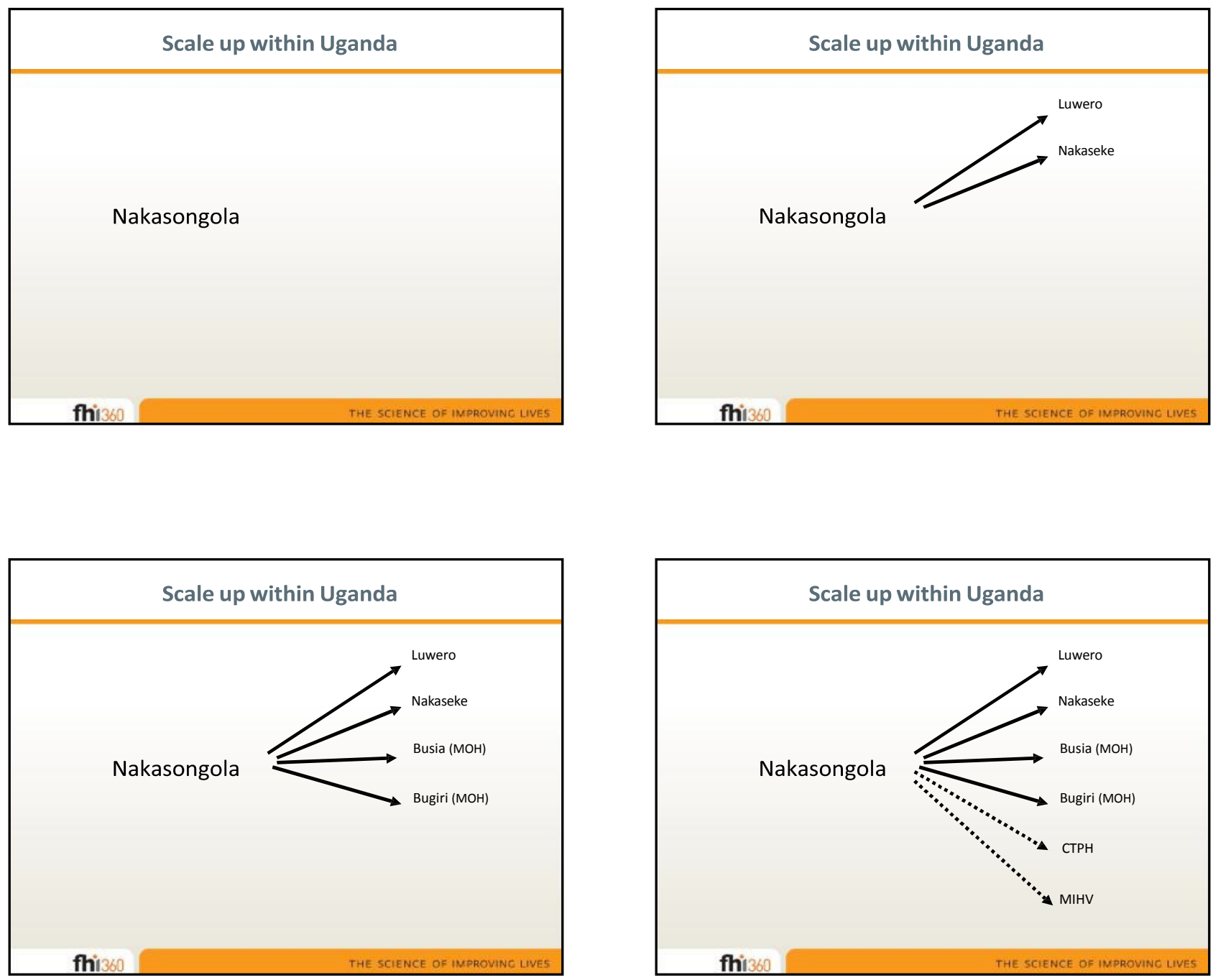


\begin{tabular}{|c|}
\hline Approach to Expansion of CBA2I \\
\hline Identify and engage potential partners \\
Advocacy and outreach to identify potential partners \\
In collaboration with partners, determine: \\
O Feasibility and need \\
Costs and benefits of implementation \\
Roles and responsibilities \\
Lessons learned \\
Involve MoH and other stakeholders in outreach and advocacy \\
Engage decision-makers at all relevant levels \\
Understand nature and timing of funding sources to guide scale up \\
\\
fhil 360
\end{tabular}

\begin{tabular}{|l|}
\hline Approach to Expansion of CBA2I \\
Implementation and Adaptation, Part I \\
Harmonize CBA2I with existing health care systems (public \\
and private) \\
Adapt data collection/M\&E tools \\
Training supervisory/management staff in both sectors \\
Integrate new data with HMIS \\
Provide support for procurement/logistics \\
Lessons learned \\
For sustainability in both sectors, CBA2I must be harmonized with \\
current systems for procurement, logistics, waste management, \\
supervision, and monitoring \\
A new contraceptive method can be added to existing program \\
without creating new management systems or incentives \\
fhil 360 THE sCiENCE OF IMPROviNC LVES \\
\hline
\end{tabular}

\begin{tabular}{|l|}
\hline Approach to Expansion of CBA2I \\
\hline Assess capacity and formalize partnerships \\
Assessment of need for CBA2I and capacity to add to existing \\
FP services \\
Strengthen CBD skills, program management, supervision and \\
M\&E \\
Coordination between private and public sector for \\
sustainability and formalizing roles (core teams) \\
Lessons learned \\
Need for CBA2I must be weighed against operational costs \\
Identified weaknesses of program must be addressed before CBA21 \\
introduced \\
District-led core team necessary for project buy-in, sustainability, and \\
monitoring \\
fhi360
\end{tabular}

\section{Approach to Expansion of CBA2I}

Training of Community Health Workers

Build in sustainability with TOT training

Include refresher training with CBA2I content

Standardize training materials across sectors

Train CHWs that meet criteria and that community respect and trust

Lessonslearned

Build flexibility into training schedule

Include sufficient time in practicum component to ensure that all

CHWs are supervised and observed for required minimum

administrations of injectable contraception before certification

fhi 360

THE SCIENCE OF IMPROVINC LIVES

\section{Approach to Expansion of CBA2I}

Implementation and Adaptation, Part 2

Promote CBA2I and sensitize communities

Coordinate with regular ongoing community sensitization meetings

Combine private and public sector resources

Include political and civil-society leaders

Lessonslearned

Ongoing community meetings can easily be used to inform local villages and citizens about the new service

Involvement of district stakeholders and community members builds awareness of CBA2I and vets the program, creating trust and confidence in the new service

fhi360 THE SCIENCE OF IMPROVINC LIVES

\begin{tabular}{|l|}
\hline \multicolumn{1}{|c|}{ Approach to Expansion of CBA2I } \\
Manage logistics and waste \\
Rely on NGOs to act as liaisons between CHWs and clinics to \\
ensure continuing supply of commodities \\
Encourage sharing between districts/health centers to avoid \\
stockouts \\
Capitalize on existing waste management systems \\
Lessons learned \\
Seed stock of commodities should be procured during training and \\
start-up \\
Stock outs will continuously pose a challenge \\
Training in logistics management before and during expansion of \\
CBA2I is key \\
fhi360
\end{tabular}




\begin{tabular}{|l|}
\hline Approach to Expansion of CBA2I \\
\hline Monitor and supervise CHWs \\
Standardize data tracking tools across sectors \\
Develop plan for supervision and M\&E \\
Lessons learned \\
Careful vetting of CHWs to ensure understanding and appropriate use \\
of data collection tools \\
Plans for supervision and M\&E must account for realities on the \\
ground, including limited finances for carrving out regular supervision \\
Important not only to ensure that CHWs are being supervised, but that \\
quality of supervision is satisfactory \\
fhi360
\end{tabular}

\section{FHI 360's approach to intervention-based} research

- Design interventions with facilitators of/barriers to scale-up in mind (CORRECT model)

Engage end-users (those who will scale) throughout

Document the process, capture the "how" to inform scale-up

Integrate costing analysis into pilot research

Package key learnings so they can be used to facilitate replication and scale-up

\begin{tabular}{|l|}
\hline \multicolumn{1}{|c|}{$\begin{array}{c}\text { Conclusion: Gaps in Research for } \\
\text { Scale Up of CBA2I }\end{array}$} \\
Assess cost-effectiveness of adding injectables to \\
CHW method mix \\
Optimize public and private sector collaboration \\
Determine best way to provide training and \\
continuous support for procurement/logistics \\
Establish mechanisms for good quality supportive \\
supervision \\
Increase CHW capacity to offer/promote full range of \\
contraceptive options \\
fhi360
\end{tabular}

Parting thought .......
"Clearly there is a need for a "science of replication";
procedures for documenting intervention content,
delivery, target populations, successes, and challenges;
and tools for identifying core elements."
Morrison, Diane M. et al. "Replicating an Intervention:
The Tension Between Fidelity and Adaptation." AIDS
Education and Prevention 21(2), 128-140, 2009.
fhi360

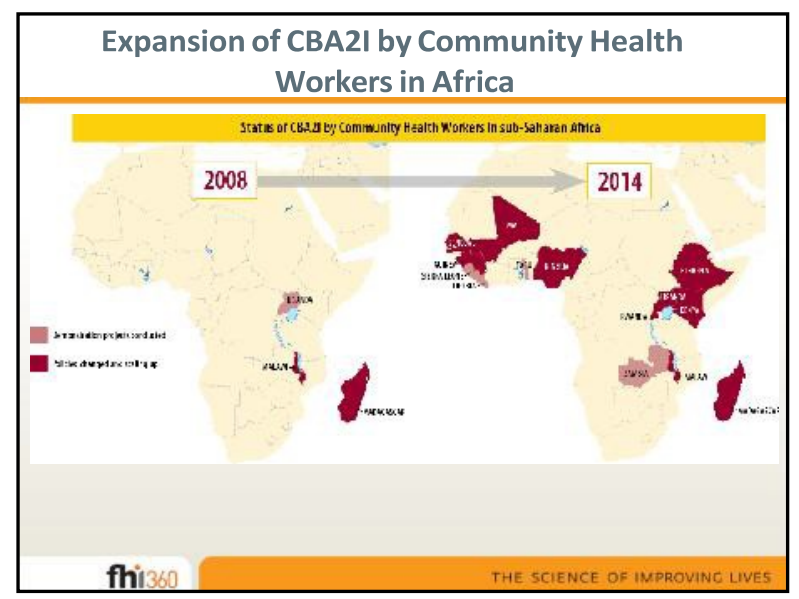




\section{Appendix 4. Notes from the Group Discussions on Research Gaps in Scale Up}

Note: Check marks and red text indicate group voting to determine priority research topics.

The discussions in the groups generated both research ideas and reflections on scale up more generally. Participants noted that there is a need to identify which are the main bottlenecks for success in scaling up interventions. This will help formulate research questions and address research gaps around scale up.

\section{BOTTLENECKS IN THE PROCESS OF SCALING UP (IDENTIFIED BY PARTICIPANTS)}

- Lack of commitment by government or stakeholders to scale up

- Divergent priorities in decentralized systems

- Money

- Conflicts between the different definitions of scale up and balancing the goals of equity and expansion

- Weak health systems in general

o Human resources, including their number and capacity to undertake new or expanded activities, and turnover.

o Management and leadership is often an important constraint.

o Limited physical infrastructure at the service delivery level

- Complex and ill-defined interventions

- Ineffective or lack of policies and guidelines to enable scale up, which is often a long process.

- Need to ensure the fidelity of the intervention while adapting to local context

- Models tested in different environments, so the core elements to be replicated are not always clear. 


\section{PROOF OF CONCEPT VS. PROOF OF IMPLEMENTATION AND THE NEED FOR AN ADAPTATION PHASE}

Participants noted that there is need for research, linked with monitoring and evaluation, throughout the process of scale up.

- When does the research come? Before and/or during scale up. It would be good to have a timeline and when relevant research is needed.

- Research methods for each of these phases

o Range of outcomes looked at - need process outcomes of the implementation as well as utilization and health outcomes.

- It is important to differentiate between studying proof of concept (does the intervention work) vs. proof of implementation (can the intervention be implemented/scaled up); there needs to be an adaption phase also which includes testing different elements of the model. Are those done simultaneously? What does it mean to "start with the end in mind"? $\checkmark \checkmark$

Proof of concept $\rightarrow$ Proof of implementation (implementation research with monitoring of scaled up intervention/innovation to see if scale has been first achieved and then maintained). Adaptation is needed between proof of concept and proof of implementation/scale-up.

\section{LEARNING FROM PAST SCALE UP EXPERIENCES}

Review of past scale up efforts both through a desk review and retrospective case studies would help answer the following questions.

- What characteristics of implementation foster its success for scale up? $\checkmark \checkmark \checkmark \checkmark \checkmark \checkmark \checkmark$

- What do we know about the components of the scaling up process from implementation experience? What elements "stuck" and which ones didn't? $\checkmark$ How long and how much time and resources does it take to scale up the intervention in different contexts?

0 This question would be best answered by retrospective analyses that documents the components of the scale up process.

o Research should also look at these processes in differing contexts, including the public and private sectors.

o Research should include a range of projects supported by various donors.

- How to lay the groundwork for scale during the pilot stage? Does the intervention hold (and work as well) when brought to scale? $\checkmark$ 


\section{IDENTIFYING FACILITATING FACTORS IN SCALE UP}

There was substantial interest in identifying what the core components of successful scale up are while recognizing that scale up will be widely context-specific. Participants noted the need to identify facilitating factors in scale up in order to focus on those in the scale up process through a meta-analysis of the literature and/or through case studies. There was some discussion about whether the facilitating factors have already been identified, at least for HIV/AIDs.

- What are factors that have facilitated scale-up and the factors that have hindered scale up? What has been tested? What has been the results? What have been the drivers of adaptation?

$\checkmark \checkmark \checkmark \checkmark \checkmark \checkmark \checkmark$

\section{ASSESSING SYSTEM READINESS FOR SCALE UP}

Participants noted that more attention needs to be paid to vertical scale up - or institutionalization of the intervention/innovation in the health and other appropriate systems. We do not know enough about the process of vertical scale up and need to document this important aspect of scale up. A number of points were made and questions were raised about this topic.

- What system elements and contextual factors are essential to scaling up? $\checkmark \checkmark \checkmark \checkmark \checkmark \checkmark \checkmark \checkmark \checkmark$

- How do we assess local system readiness (e.g. delivery systems, governance structures, etc.)? What are the processes that best facilitate institutionalization of scale (vertical scale up)?

- How can the policy environment and political commitment be strengthened for enabling scale up?

- What are the environmental influences on scale up?

- Scale up plans should consider all six health system strengthening components (service delivery; health workforce; information; medical products, vaccines and technologies; financing; and leadership and governance). A weak link in one of them could greatly jeopardize the successful implementation of a scale up plan. How do weak health system pillars affect scale up and to what degree?

- What impacts on scale up can be attributed to whether systems are centralized vs. decentralized? Integrated vs. vertical? Can we generalize about approaches or models for centralized vs. decentralized vs. hybrid systems?

- For improving the chances for success during scale up, capacity building needs should be addressed and assessed from the start.

- Given limited human resources and turnover, what are the best ways to scale up? training in family planning and build capacity that will last.

- Assessment tools are needed to guide the process of scale up, both for vertical and horizontal scale up. 
- Evaluating facilities through a set of metrics that will validate the tools as being ready to be part of scale up process. These types of tools will enhance the scale up process

\section{UNDERSTANDING THE TIME DIMENSION AND INCREASING THE PACE OF SCALE UP}

Participants noted that it may take 10-12 years for scale up to be complete.

- How can we shorten the scale up timeframe? Need to identify better ways to achieve scale up at a much faster pace. $\checkmark \checkmark \checkmark \checkmark \checkmark \checkmark \checkmark \checkmark \checkmark$

\section{IMPLEMENTING MONITORING AND EVALUATION (M\&E) SYSTEMS LINKED TO RESEARCH}

Participants noted the clear need for strong M\&E systems related to scale up, including a monitoring and documentation processes that allows us to learn from scale up experiences.

- What are the best ways to enable or develop the capacity of stakeholders in-country to systemically implement and monitor scale-up efforts? What skills are needed? What resources are needed? $\checkmark \checkmark \checkmark \checkmark$

o This also implies a large TA agenda that would support countries to develop capacities to promote scale up in areas such as M\&E, context-specific operations research, and implementing systematic models of scale up.

o Monitoring data should be used to identify problems, and then research will answer questions. While we know that this should be the case (M\&E leading to research leading to program improvement), it is often not implemented due to lack of time or money. $\checkmark$

o Good monitoring systems are needed for scale up, and these systems may be different (or over and above) those used for routine program monitoring. This monitoring effort is akin to quality improvement processes.

o There are challenges with monitoring data that undermines its usefulness in tracking scale-up. It often lags behind program experience (can't keep up with the intervention), is of variable quality (especially in the public sector), and looks only at program outputs and outcomes.

o Layer on prospective monitoring and documentation processes that allow us to learn from scale. $\checkmark \checkmark$

0 How do we show that donors need to invest better in monitoring of scale up, and any additional research to address identified gaps? Should we frame it as investing in quality improvement (as opposed to research) and recommend that all projects earmark 10-20 percent of their budget for quality improvement activities? 
o Are there better tools, if any, to monitor and evaluate the scale up process and ensure good supervision of the scale up plan, and monitoring of milestones and deliverables.

\section{ASSESSING THE ECONOMICS OF SCALE UP (COST AND FINANCING)}

- Need to develop scale up plans that are in balance with available resources. More costing studies on scale up are needed to advise decision makers about the cost of scale up plans.

\section{BEGINNING WITH THE END IN MIND: REAL WORLD VS. BELLS AND WHISTLES APPROACHES}

- Is it better for a pilot to be done in a "real world" situation or to be implemented using a "bells and whistles" approach? $\checkmark$

- During the proof of concept stage - consider having a few arms to the study - one can be the bells and whistles model (full fidelity) and the others can be scaled-down versions of the intervention - to get evidence on which components are needed to get impact and which can be pared down in the intervention when scaled up and still get impact.

\section{DIFFUSION OF SCALE UP; IS THERE A TIPPING POINT?}

- When scale up is being conducted in certain areas, is there any diffusion of the intervention to adjacent areas? Is there a tipping point for scale up at which point the innovation/intervention will expand spontaneously? $\checkmark \checkmark \checkmark$

\section{LEVERAGING AND LEARNING FROM THE PRIVATE SECTOR}

- What can we leverage and learn from private/commercial sector experiences in scaling up services (e.g. scaling up Marie Stopes franchise model based on expected and established performance standards.)? $\checkmark \checkmark \checkmark \checkmark \checkmark$

- How can public and private sectors work together to collaborate on scale up?

\section{SUSTAINABILITY OF SCALE-UP}

- What is the definition of sustainable scale up, particularly when there is such dependency on donor assistance? Can new definitions be developed? 


\section{GETTING INTERVENTIONS ACCEPTED BY THE GOVERNMENT}

- Scale up is political. How does efficiency play a role in decision making? Getting interventions accepted by the government - what is the cost, time, etc. to do so? Need to have that discussion.

o Donors could help fund this analysis so governments can make evidence-informed decisions.

- How do we communicate the need for scale up (particularly vertical) to key stakeholders?

\section{DETERMINING WHAT IS WORTH SCALING UP?}

- How do we decide when interventions should be scaled up? What is worth scaling up?

\section{EQUITY, GENDER, AND PARTICIPATION}

- How can we maintain fidelity and equity of access while simultaneously reaching scale? (Alternatively how can we avoid losing equity when reaching scale) $\checkmark \checkmark \checkmark \checkmark$

- How does gender influence scale up?

- How can civil society contribute to ensuring services are successfully scaled up and sustained?

\section{COMPARING SCALING-UP FRAMEWORKS}

- Are there other (improved) frameworks for scale? Or tools to support scale up?

- If we want to take a systems lens for scale up, would it help to have an organizing framework? Or do the existing frameworks (e.g. ExpandNet) serve that purpose? Would having a framework organized around the WHO health systems building blocks help?

- Which of the systematic approaches to scaling up work best?

- Which adoption models lead to greater uptake and use of family planning?

\section{COMPILING EXISTING TOOLS}

- How can we compile/integrate existing tools for capacity building/scaling up/etc.?

- What validated metrics exist to assess scale-up? Do we need to validate/develop new metrics? 


\section{BUILDING CAPACITY FOR RESEARCH ON SCALE UP}

- Any research on scale-up must include research capacity building, including for data utilization.

\section{USING CORE FUNDS TO FOSTER INNOVATION}

One question posed to the group was the appropriate use of USAID's core funds vs. field support funds for research on scale up. Participants noted that projects to scale up interventions are generally considered service delivery projects, with some funding for $\mathrm{M} \& \mathrm{E}$ but generally no funding for research. Participants made the following points:

- Use of core funds related to scale up should be for innovative interventions - to try them and potentially take them from proof of concept to proof of implementation (with the adaptation phase). Once those are determined, the scale up should be funded through field support.

- There is a need to shift from RFAs that focus on innovative interventions to ones that focus on innovative scale up

- TA for scale up should including funding for a learning agenda, including monitoring and problem solving during scale 


\section{Evidence Project}

Population Council

4301 Connecticut Avenue, NW, Suite 280

Washington, DC 20008 USA

Tel : +1 2022379400

Email : evidenceproject@popcouncil.org

evidenceproject.popcouncil.org 